\title{
CAPITAL SOCIAL E DESENVOLVIMENTO SUSTENTÁVEL NO CHILE ${ }^{1}$
}

\author{
Patricio Valdivieso
}

\begin{abstract}
Resumo
O artigo apresenta indicadores de cultura política e de capital social na cidade de Santiago do Chile, baseados na execução do Projeto FONDECYT 1071073 e em uma pesquisa aplicada na execução do projeto Desenvolvimento Sustentável e Capital Social na promoção da Cidadania e Qualidade de vida na América Latina, promovido pelo Núcleo de Pesquisa sobre a América Latina (NUPESAL), de Porto Alegre, Brasil.
\end{abstract}

Palavras-Chave: Capital Social; Democracia; Participação.

\begin{abstract}
This article present indicators of political culture and social capital in the city of Santiago de Chile, based on the implementation of the project FONDECYT 1071073 and a survey executed in the implementation of the project Desenvolvimiento Sustentável e Capital Social na promoção da Cidadania e Qualidade de vida na América Latina in Santiago, sponsored by the Núcleo de Pesquisa sobre a América Latina (NUPESAL), from Porto Alegre, Brasil.
\end{abstract}

Key-Words: Social Capital; Democracy; Participation.

\section{Introdução}

Este artigo apresenta indicadores de cultura política e capital social na cidade de Santiago do Chile, baseados no survey realizado para o projeto Desenvolvimento Sustentável e Capital Social na promoção da Cidadania e Qualidade de vida na América Latina.

A pesquisa foi realizada por amostragem em cinco comunas de Santiago: Quinta Normal, La Granja, Recoleta, Lo Espejo e Pedro Aguirre Cerda, representativas dos estratos C e D. Foram selecionadas 100 pessoas em cada comuna, obtendo-se um total de 500 entrevistados, $50 \%$ homens e $50 \%$ mulheres.

\footnotetext{
1 Agradecimentos ao apoio concedido ao Projeto FONDECYT 1071073, cujos fundos tornaram possível a elaboração destas notas de pesquisa, e ainda ao CNPq, cujo apoio financeiro permitiu a aplicação da primeira pesquisa em Santiago, em outubro de 2005, pelo Instituto de Sociologia da Pontifícia Universidade Católica de Chile.
} 


\section{Perfil dos Entrevistados}

A maioria dos entrevistados é de jovens com menos de 25 anos $(41,2 \%)$. A freqüência de entrevistados diminui à medida que a idade aumenta, como pode ser constatado na tabela seguinte.

Tabela 1. Idade em faixas

\begin{tabular}{lcc}
\hline \multicolumn{1}{c}{ Idade recodificada } & Freqüência & \% \\
\hline até 25 anos & 206 & 41,2 \\
26 a 50 anos & 165 & 33,0 \\
51 a 75 anos & 115 & 23,0 \\
mais de 75 anos & 14 & 2,8 \\
\multicolumn{1}{c}{ Total } & 500 & 100,0 \\
\hline
\end{tabular}

A maioria dos entrevistados tem escolaridade média, seja ela completa $(32,4 \%)$ ou incompleta $(29,8 \%)$. Em seguida, a escolaridade mais freqüente é a básica incompleta com 13,6\% dos entrevistados. Somente 2,6\% possuem curso superior completo e apenas uma pessoa $(0,2 \%)$ declarou ser pós-graduada. Esses resultados são coerentes considerando que o campo da pesquisa limitou-se a comunas representativas dos estratos socioeconômicos C e D.

Tabela 2. Escolaridade

\begin{tabular}{lccc}
\hline \multicolumn{1}{c}{ Educação } & Freqüência & \% \\
\hline Básica incompleta ou menos & 68 & 13,6 \\
Básica completa & 55 & 11,0 \\
Média incompleta ou média técnica completa & 149 & 29,8 \\
Média completa ou superior técnica incompleta & 162 & 32,4 \\
Universitária incompleta ou superior técnica completa & 52 & 10,4 \\
Universitária completa & 13 & 2,6 \\
Pós-graduação & 1 & 0,2 \\
\hline \multicolumn{2}{c}{ Total } & 500 & 100,0 \\
\hline
\end{tabular}

Esses dados podem ser melhor visualizados na figura seguinte. 
Figura 1. Percentual de entrevistados por nível educacional

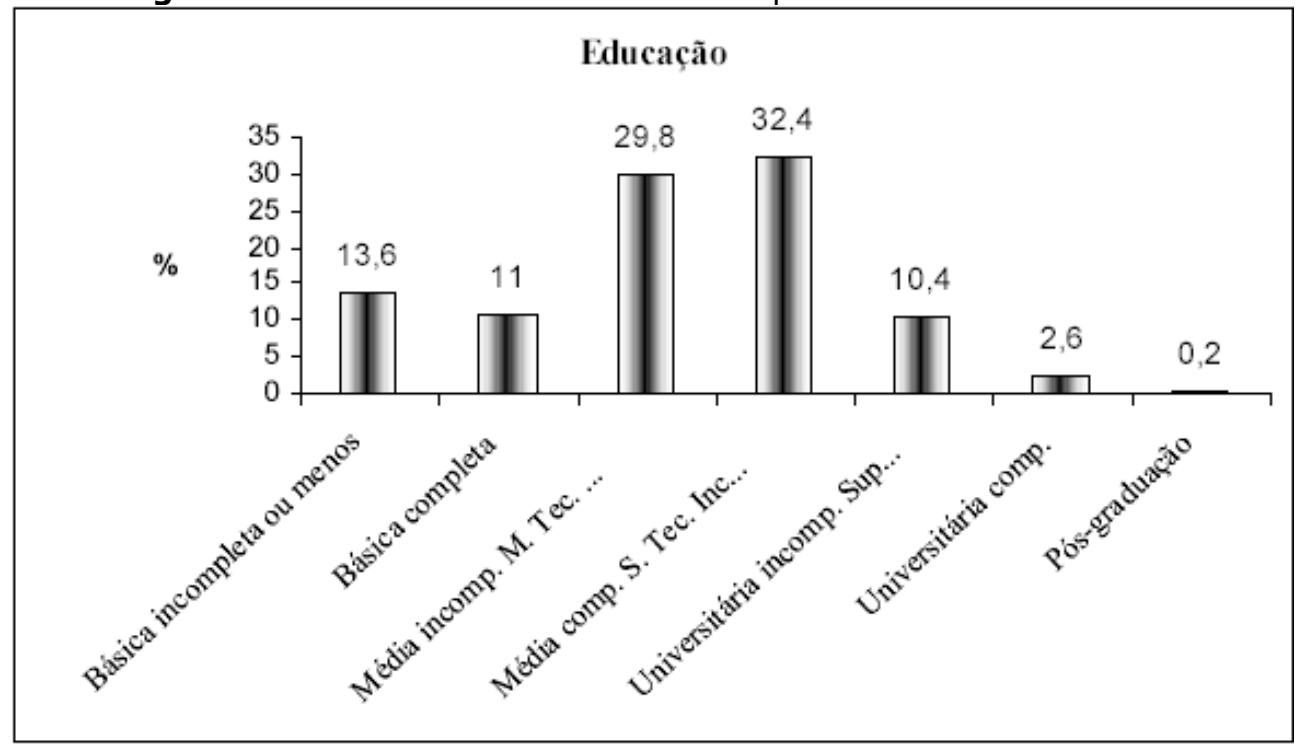

Quanto ao estado civil, a amostra compõe-se basicamente de pessoas solteiras $(43,0 \%)$ e casadas que vivem com o cônjuge $(36,4 \%)$. O percentual das outras categorias é relativamente baixo, como pode ser constatado na figura seguinte.

Figura 2. Percentual dos entrevistados segundo o estado civil

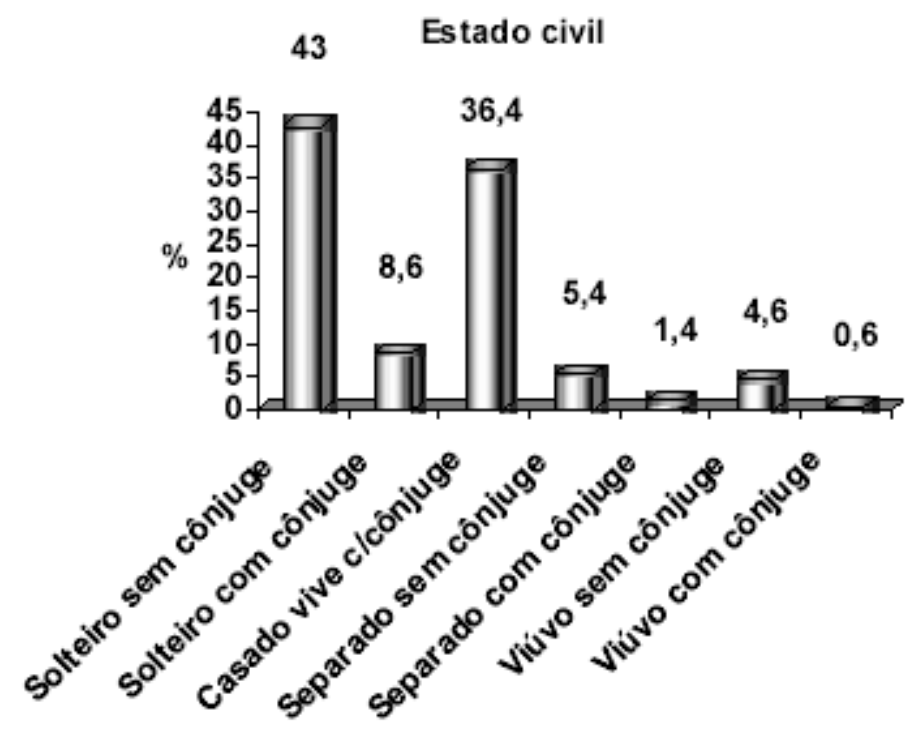

A renda familiar da maioria está abaixo de $\$ 300.000$ pesos ( $R \$$ 1560,00 tc: $1 / 3$ ), com $15,4 \%$ dos entrevistados na faixa mais baixa de 
renda, menos de $\$ 100.000$ pesos ( $R \$ 600,00$ ). A faixa mais freqüente foi a de $\$ 100.000$ a $\$ 200.000$ pesos e $9,2 \%$ declararam que têm uma renda familiar superior a $\$ 500.000$.

Tabela 3. Distribuição dos entrevistados segundo a renda familiar

\begin{tabular}{|c|c|c|}
\hline Ingresso familiar & Freqüência & $\%$ \\
\hline Menos de $\$ 100.000$ & 77 & 15,4 \\
\hline Entre 100.001 e 200.000 & 150 & 30,0 \\
\hline Entre 200.001 e 300.000 & 104 & 20,8 \\
\hline Entre 300.001 e 500.000 & 81 & 16,2 \\
\hline Entre 500.001 e 1.000 .000 & 34 & 6,8 \\
\hline Entre 1.000 .001 e 1.500 .000 & 11 & 2,2 \\
\hline Entre 1.500 .001 e 2.000 .000 & 1 & 0,2 \\
\hline NS-NR & 42 & 8,4 \\
\hline Total & 500 & 100,0 \\
\hline
\end{tabular}

A religião professada pela maioria dos entrevistados é a Católica, $58,6 \%$, em seguida a Protestante ou Evangélica, com um significativo $19,6 \%$, como pode ser visualizado na figura seguinte. A categoria Outra religião também apresentou um significativo 19,4\% evidenciando a penetração de outras religiosidades no cenário chileno. Nenhum dos entrevistados declarou não ter religião.

Figura 3. Distribuição dos entrevistados por religião, em porcentagem

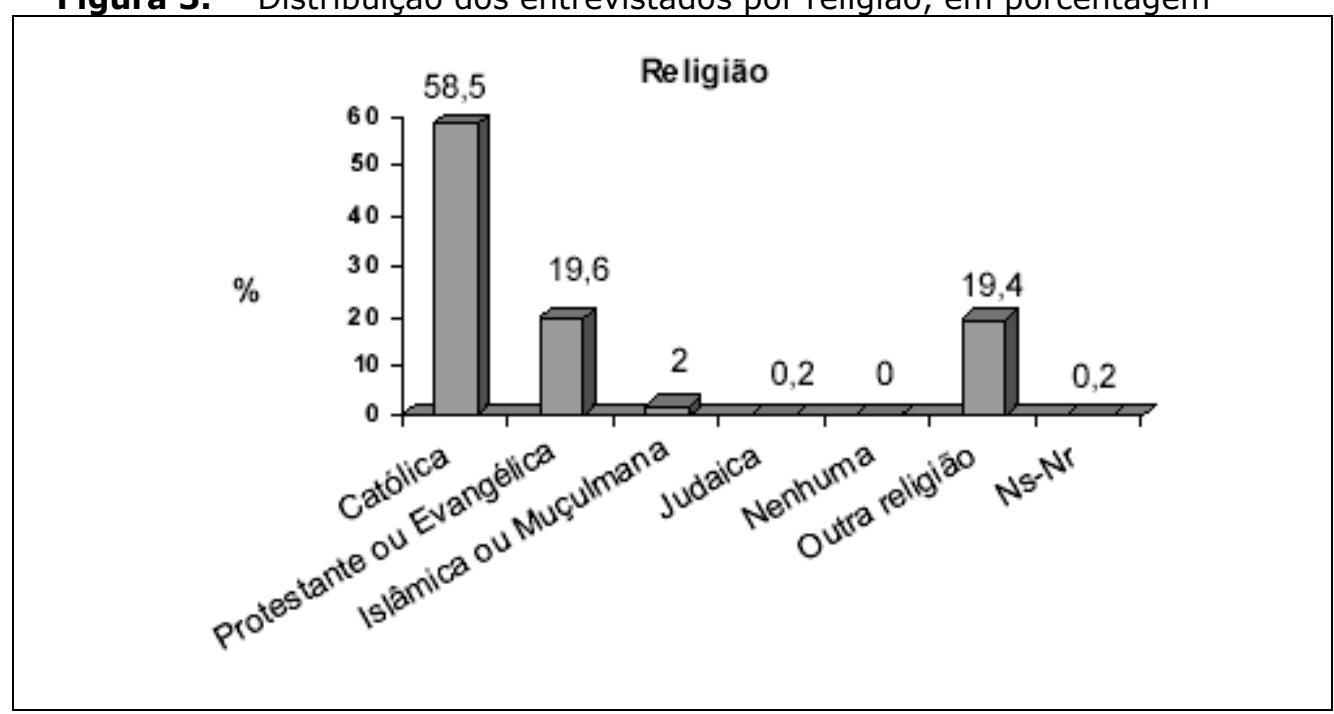


Em suma, é este o perfil dos entrevistados: jovem, solteiro(a), com educação média tendendo à média completa, com renda familiar de até 300 mil pesos e que professa a religião católica.

\section{Política}

A maioria dos entrevistados não se interessa por política (57,0\%). Somente 15,4\% declararam ter interesse. Há associação entre interesse pela política e o sexo ${ }^{2}$. Os homens se interessam mais do que as mulheres.

Figura 4. Interesse por política segundo sexo

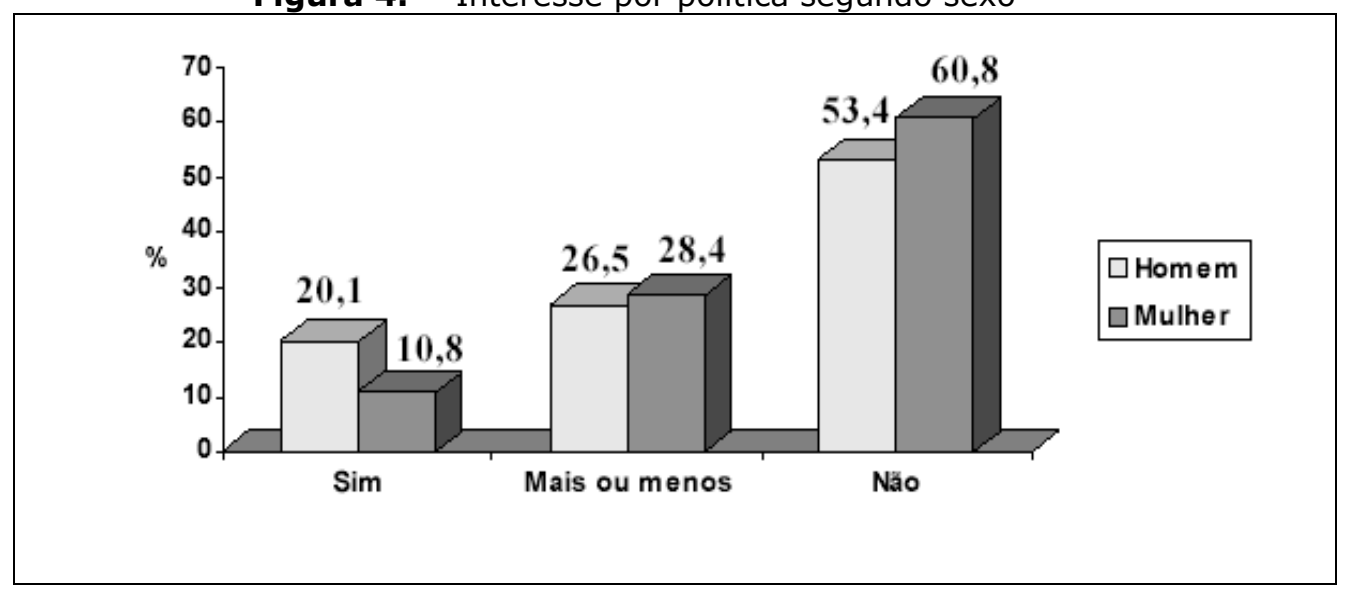

Essa figura mostra que tanto homens como mulheres, em geral, não se interessam pela política. Entretanto, é evidente que há mais homens $(20,1 \%)$ que se interessam e mais mulheres $(60,8 \%)$ que não se interessam por política.

Também foi encontrada relação com a instrução ${ }^{3}$. O interesse pela política tende a aumentar à medida que o nível de escolaridade aumenta. Não foi possível detectar associação com a idade.

2 Para verificar a relação entre sexo e interesse pela política utilizou-se o teste de independência do qui-quadrado. Obteve-se um qui-quadrado com 2 graus de liberdade= 8,317 com $p=0,016$.

${ }^{3}$ Qui-quadrado com 12 graus de liberdade $=39,415$ com $p<0,001$. 
Figura 5. Percentual dos entrevistados segundo o interesse pela política

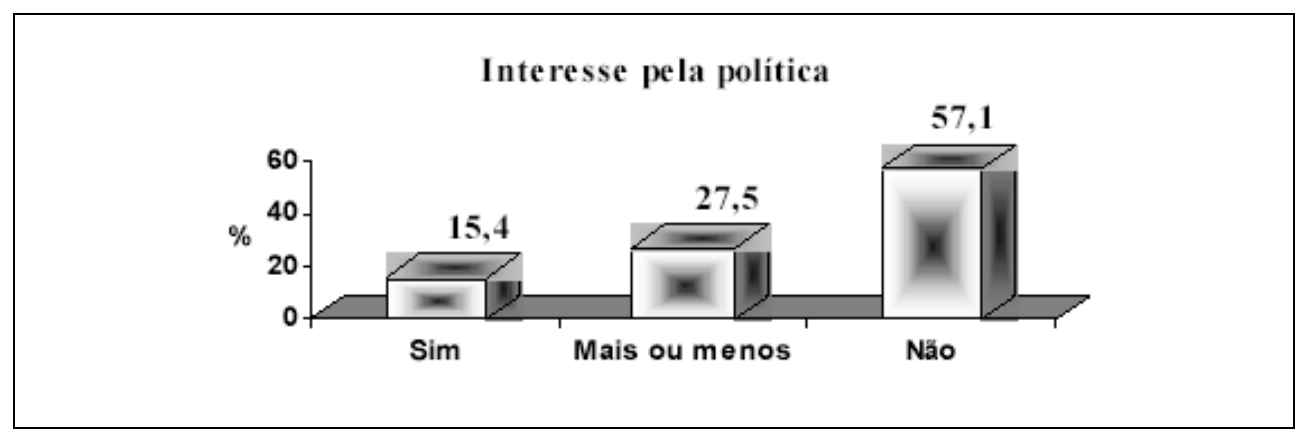

Embora o interesse pela política seja pouco, a maioria dos entrevistados $(56,1 \%)$ declarou que costuma informar-se sobre assuntos políticos. Entretanto, os resultados indicam que o interesse se limita a informar-se, pois, conversar sempre sobre o assunto com amigos ou parentes é coisa que somente uma minoria faz. Somente $11,6 \%$ declararam que conversam sempre com familiares e $10,5 \%$ conversam sempre com amigos. Por outro lado, 48,8\% declararam que conversam sobre política com seus familiares algumas vezes e a porcentagem cai para $34 \%$ quando se trata de conversar com amigos. A figura seguinte mostra esta situação.

Figura 6. Percentual de entrevistados que conversam sobre política com amigos e parentes

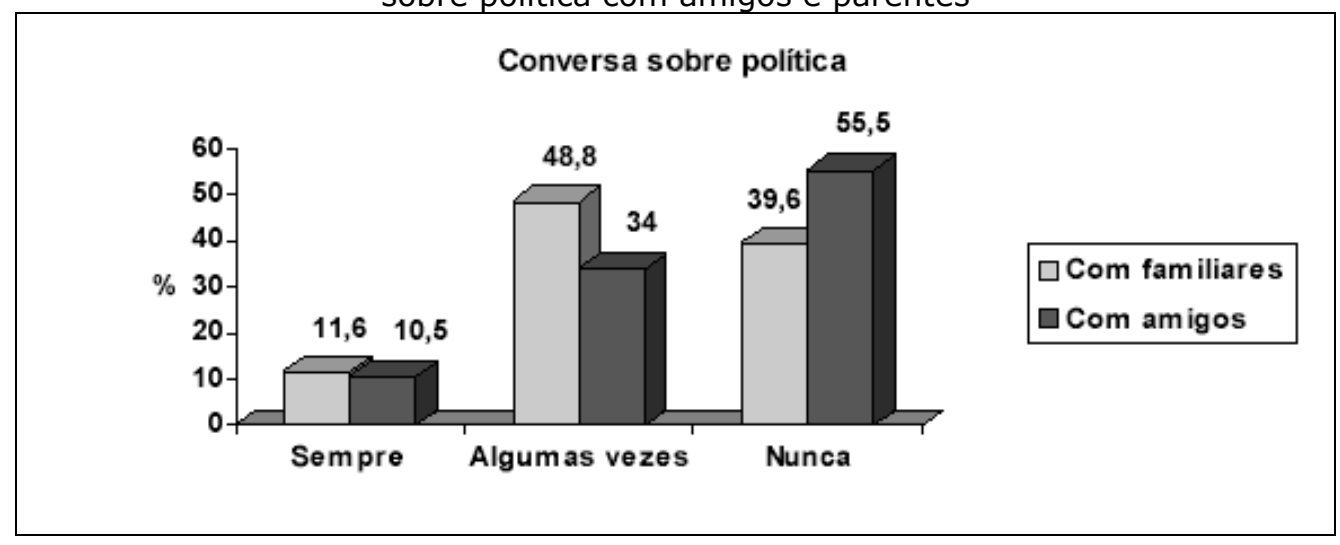

Em relação a conversar com os amigos, a concentração de respostas na categoria algumas vezes parece ser um fenômeno mais 
generalizado do que se possa pensar, ou seja, as pessoas, em geral, não costumam falar freqüentemente de política. Isso fica evidenciado se compararmos este resultado com os obtidos na Pesquisa Mundial de Valores (World Values Survey- WVS) realizada em vários países do mundo sob a coordenação do prof. Ronald Inglehart, da Universidade de Michigan. Foram selecionados alguns países da Europa e da América Latina para fazer um contraponto com os dados obtidos nesta pesquisa (Chile 2005). Utilizou-se a onda de 1995 da WVS. A tabela seguinte mostra os resultados desta questão na França, Grã-Bretanha, Alemanha, Itália, Peru, Venezuela e Uruguai.

Tabela 4. Freqüência com que as pessoas costumam falar de política com os amigos, em percentual

\begin{tabular}{l|c|c|c|c|c|c|c|c|c}
\multicolumn{7}{c}{ falar de política com os amigos, em percentual } \\
\hline $\begin{array}{l}\text { Costuma } \\
\text { conversar de } \\
\text { política com } \\
\text { seus amigos }\end{array}$ & $\begin{array}{l}\text { Chile } \\
\mathbf{2 0 0 5}\end{array}$ & $\mathbf{1 9 9 5}$ & $\mathbf{1 9}$ & França & G.B. & Alemanha Itália & Peru & Venezuela & Uruguai \\
\hline Sempre & 10,4 & 14,2 & 11,8 & 12,6 & 24,5 & 12,4 & 9,8 & 11,6 & 16,4 \\
Às vezes & 34,0 & 40,1 & 52,5 & 51,5 & 59,8 & 44,3 & 53,4 & 41,6 & 38,2 \\
Nunca & 55,5 & 45,7 & 35,7 & 36 & 15,7 & 43,3 & 36,8 & 46,8 & 45,2 \\
\hline
\end{tabular}

Observa-se que em geral a maior freqüência das respostas está na categoria às vezes, seguida da categoria nunca. A categoria sempre é a que menor freqüência apresenta, como pode ser visualizado na figura seguinte.

Figura 7. Freqüência com que falam de política com amigos

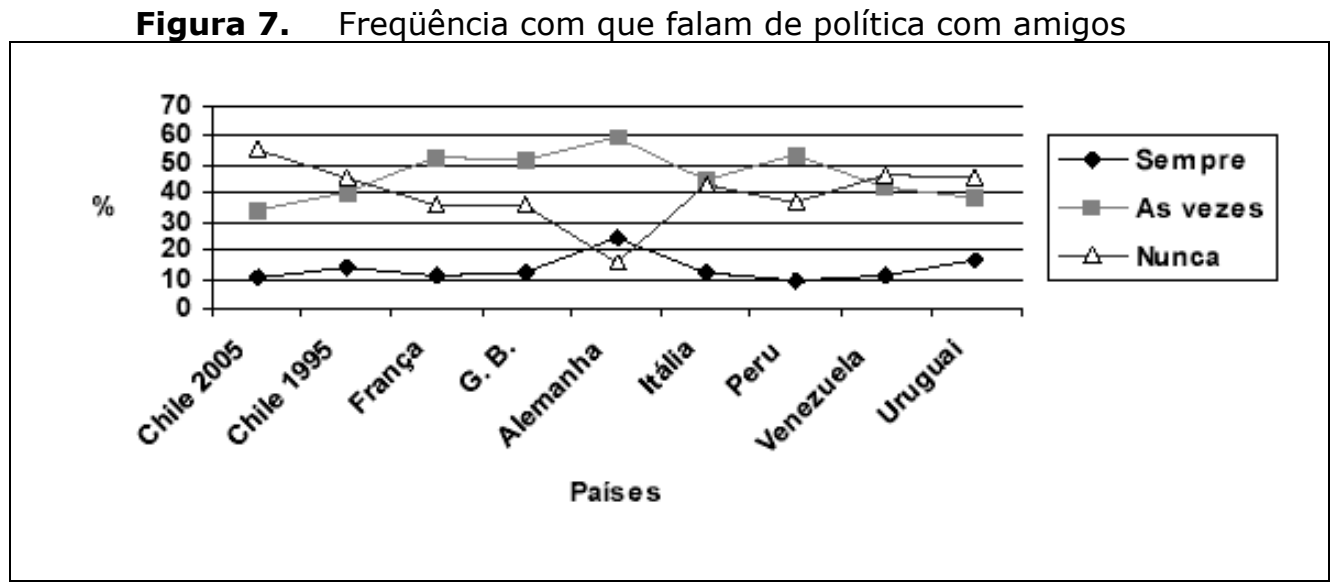


Com exceção da Alemanha, que apresentou uma porcentagem menor de pessoas que responderam nunca, todos os outros países apresentam a menor porcentagem de respostas sempre. Observa-se que o Chile apresentou em 1995 (WVS) uma proporção de 14,2\% de pessoas que conversam sempre com amigos, resultado que nesta pesquisa caiu para $10,4 \%$. É importante chamar a atenção para o fato de que a pesquisa do WVS 1995 foi de caráter nacional, enquanto esta abrange somente 5 comunas.

Como já evidenciado, os homens e as pessoas de mais instrução são os que mais se interessam pela política. Conversar sobre política com os amigos também tem forte correlação com o sexo ${ }^{4}$ e a idade ${ }^{5}$. Os homens conversam mais de política com seus amigos do que as mulheres e quanto maior o nível educacional mais as pessoas conversam sobre política com os amigos, como pode ser constatado na figura seguinte.

Figura 8. Percentual de pessoas que falam sobre política com seus amigos segundo o nível educacional

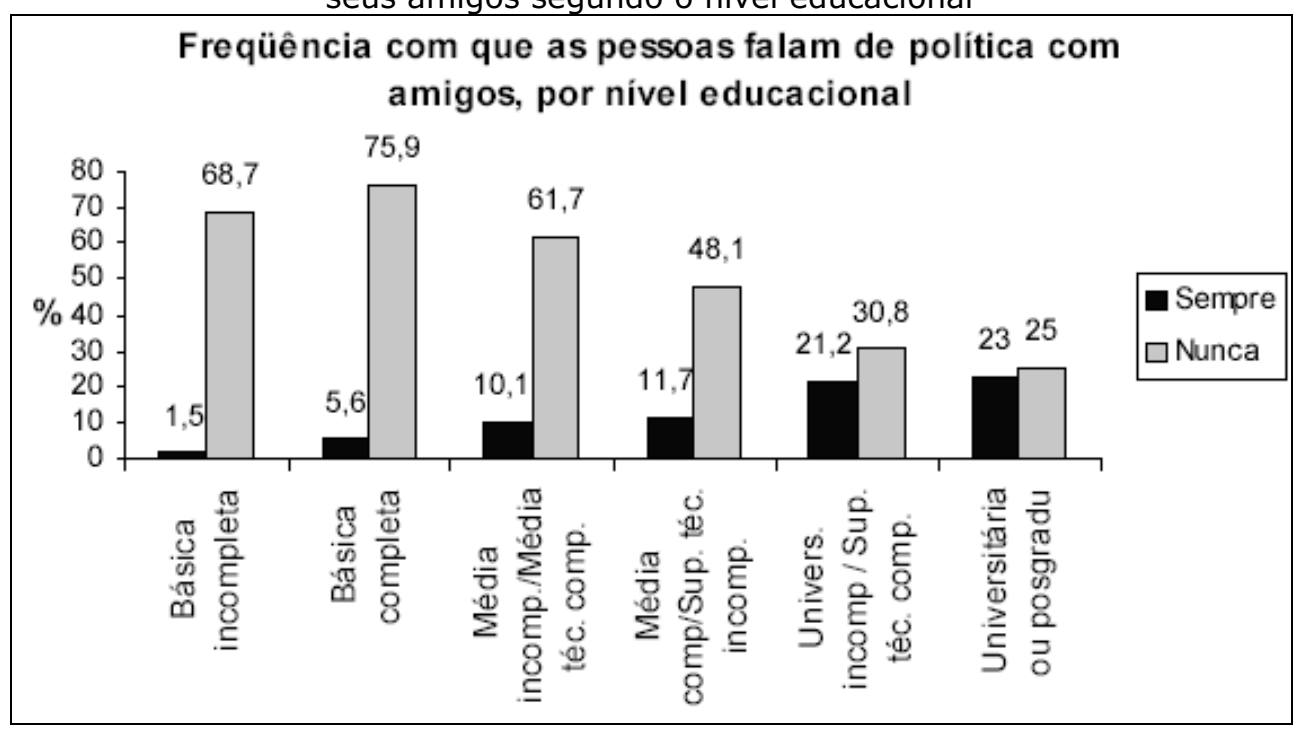

${ }^{4}$ Qui-quadrado com 12 g.l. $=50,382$ e $p<0,001$. Para a realização do teste do quiquadrado juntaram-se as categorias universitária completa e pós-graduação.

${ }^{5}$ Qui-quadrado com 2 g.l. $=16,912$ e $p<0,001$. 
Entretanto, observa-se que mesmo entre os universitários a porcentagem dos que nunca conversam de política com seus amigos ainda é maior do que a dos que conversam sempre, embora se possa dizer que já há certo equilíbrio entre essas porcentagens.

Em relação aos problemas do país, a maioria $(44,3 \%)$ declarou que conversa algumas vezes sobre o assunto e $22 \%$ declararam que nunca o fazem.

Figura 9. Freqüência com que fala dos problemas do país com seus amigos

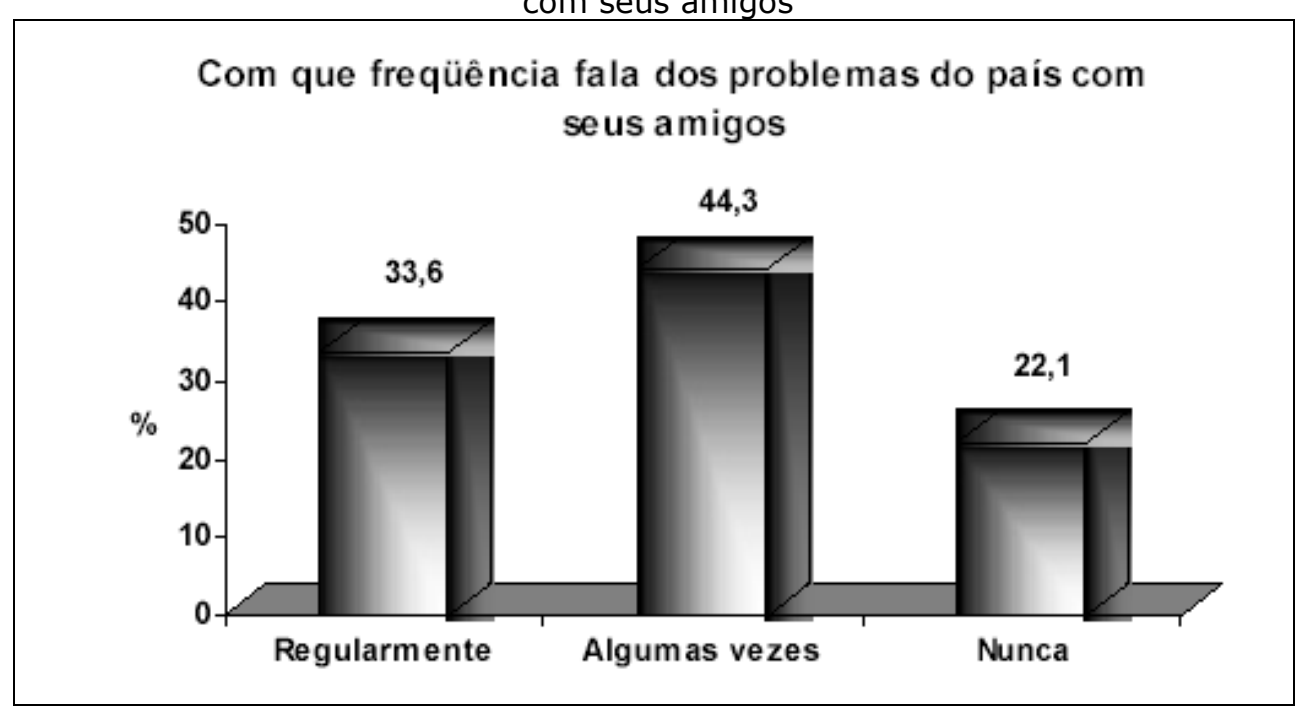

O funcionamento da democracia não está agradando a maior parte das pessoas. A maioria está dividida entre pouco satisfeita $(38,2 \%)$ e insatisfeita $(37,2 \%)$. E isso ocorre de maneira generalizada, ou seja, não foi encontrada relação das respostas com o sexo ou a instrução do respondente.

Tabela 5. Satisfação com democracia

\begin{tabular}{|c|c|c|}
\hline $\begin{array}{l}\text { Em relação ao funcionamento da } \\
\text { democracia no Chile, você se sente }\end{array}$ & Freqüência & $\%$ \\
\hline Satisfeito & 94 & 18,8 \\
\hline Pouco satisfeito & 191 & 38,2 \\
\hline Insatisfeito & 186 & 37,2 \\
\hline NS-NR & 29 & 5,8 \\
\hline Total & 500 & 100,0 \\
\hline
\end{tabular}


A descrença da população na política parece ser a tônica. Somente $12,8 \%$ dos entrevistados estão em desacordo com a afirmação de que todos os políticos são corruptos. Somente 5,0\% discordam da afirmação de que os políticos prometem, mas não cumprem e 44,4\% discordam que o Estado seja eficiente na utilização dos recursos públicos.

Tabela 6. Opinião em relação às afirmações seguintes

\begin{tabular}{l|lr}
\hline \multicolumn{1}{c|}{ Itens } & \multicolumn{1}{c}{ Respostas } & \% \\
\hline Todos os políticos são corruptos & Concorda & 32,0 \\
& Concorda em parte & 51,6 \\
& Discorda & 12,8 \\
& NS/NR & 3,6 \\
\hline Os políticos prometem, e depois não cumprem & Concorda & 68,0 \\
& Concorda em parte & 26,0 \\
& Discorda & 5,0 \\
& NS/NR & 1,0 \\
\hline O Estado é eficiente na utilização dos recursos & Concorda & 17,0 \\
públicos & Concorda em parte & 36,4 \\
& Discorda & 44,4 \\
& NS/NR & 2,2 \\
\hline
\end{tabular}

\section{Participação Política}

Aos entrevistados foi apresentada uma lista de associações e grupos para que dissessem se costumavam participar, se haviam participado no passado, ou não participavam. Os resultados evidenciaram que a participação política entre eles é, de maneira geral, baixa. Destacam-se as associações religiosas $(26,2 \%)$ como de maior freqüência. A Coleta de assinaturas $(13,0 \%)$ e os Atos públicos $(10,6 \%)$ são, juntamente com a participação religiosa, os únicos em que a freqüência ultrapassou os 10\%. Associações comunitárias, Juntas de vecinos $^{6}$, manifestações, greves, partidos políticos, entre outros, tiveram resultado muito baixo. A figura seguinte mostra os percentuais de respostas SIM para essas diversas categorias de participação.

\footnotetext{
${ }^{6}$ Este termo será mantido em espanhol já que não há correspondente na estrutura administrativa brasileira.
} 
Figura 10. Percentual de entrevistados que participam de grupos

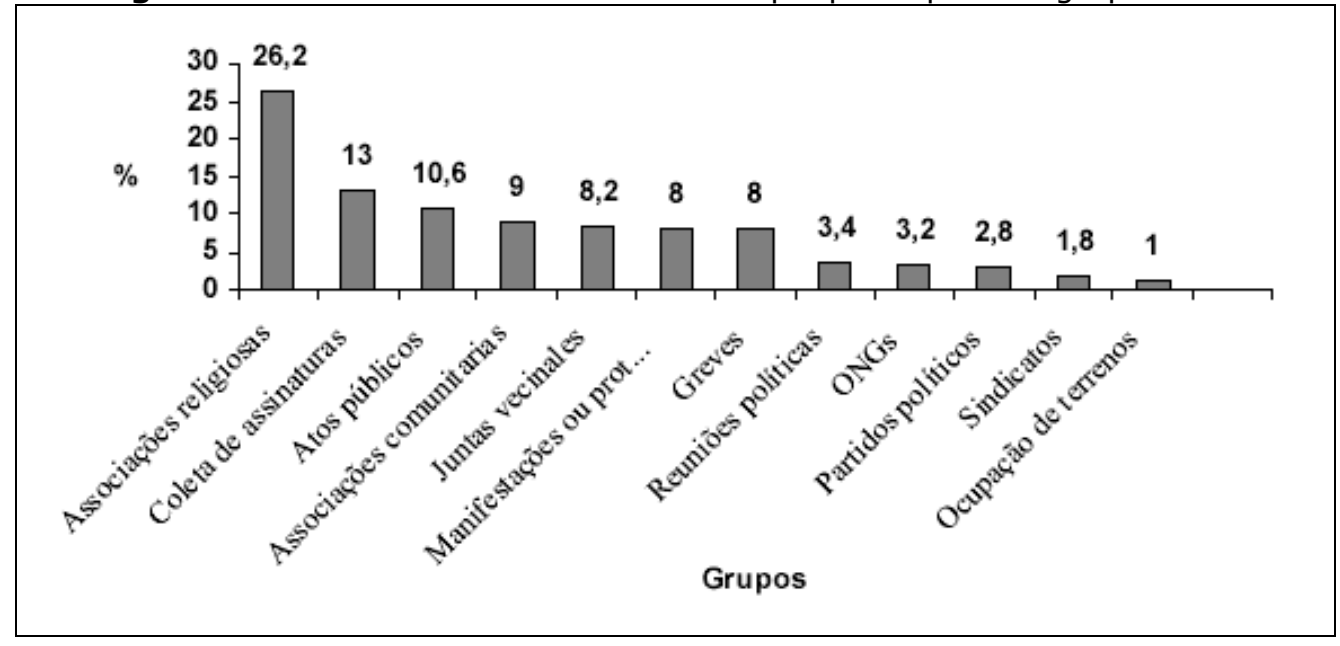

O baixo percentual de pessoas que participam de grupos concentra as resposta na categoria Não, o que dificulta a aplicação do teste qui-quadrado, pois o teste perde a sua robustez. Entretanto, mesmo com resultados que devem ser olhados com cautela, a análise do cruzamento da participação em grupos com as comunas revelou associação com algumas das variáveis como atos públicos, associações comunitárias, associações religiosas, sindicatos, juntas vecinales, coleta de assinaturas, e manifestações ou protestos. As variáveis partidos políticos, reuniões políticas, ONGs e ocupação de terrenos ou prédios não apresentaram relação de dependência com comuna. Ou seja, não há diferença significativa da participação nesses grupos nas diferentes comunas.

Para atos públicos ${ }^{7}$ e juntas vecinales ${ }^{8}$ destacam-se como comunas que tendem a participar mais Lo Espejo e Recoleta. Pedro Aguirre destaca-se em participou no passado.

Em associações comunitárias ${ }^{9}$, associações religiosas ${ }^{10}$, coleta de assinaturas $^{11}$, manifestações ou protestos ${ }^{12}$ e greves $^{13}$ é a comuna Lo

\footnotetext{
7 Qui-quadrado com 8 g.l. $=29,302$ e $p<0,001$.

${ }^{8}$ Qui-quadrado com 8 g.l. $=27,036$ e $p=0,001$.

${ }^{9}$ Qui-quadrado com 8 g.l. $=29,569$ e $p<0,001$.

${ }^{10}$ Qui-quadrado com $8 \mathrm{~g} . \mathrm{I}=65,180$ e $\mathrm{p}<0,001$.

${ }^{11}$ Qui-quadrado com $8 \mathrm{~g} . \mathrm{I} .=51,662$ e $\mathrm{p}<0,001$.

${ }^{12}$ Qui-quadrado com 8 g.l. $=36,752$ e $p<0,001$.

${ }^{13}$ Qui-quadrado com 8 g.l. $=48,628$ e $p<0,001$.
} 
Espejo que mais tende a participar, enquanto Quinta Normal destaca-se por não participação. Pedro Aguirre privilegia a resposta participou no passado.

Em sindicatos é a comuna de Recoleta que tende a participar mais e Pedro Aguirre destaca-se, novamente, como a comuna que participou no passado. Essa constante tendência da comuna Pedro Aguirre de sobressair na categoria participou no passado pode estar indicando que ela já foi muito mais ativa e que agora está em processo de arrefecimento.

La Granja destaca-se por privilegiar a não participação em vários grupos como pode ser constatado no quadro seguinte, que sintetiza quais as comunas que tendem a ser mais participativas ou não.

Quadro 1.

Relação entre participação em grupos e comunas

\begin{tabular}{|l|c|c|}
\hline \multicolumn{1}{|c|}{$\begin{array}{c}\text { Tipos de } \\
\text { participação }\end{array}$} & $\begin{array}{c}\text { Comunas que apresentam } \\
\text { maior tendência à } \\
\text { participação }\end{array}$ & $\begin{array}{c}\text { Comunas que apresentam } \\
\text { maior tendência à não } \\
\text { participação }\end{array}$ \\
\hline Atos públicos & $\begin{array}{c}\text { Lo Espejo } \\
\text { Recoleta }\end{array}$ & $\begin{array}{c}\text { La Granja } \\
\text { Quinta Normal }\end{array}$ \\
\hline $\begin{array}{l}\text { Associações } \\
\text { comunitárias }\end{array}$ & Lo Espejo & Quinta Normal \\
\hline $\begin{array}{l}\text { Associações } \\
\text { religiosas }\end{array}$ & $\begin{array}{c}\text { Lo Espejo } \\
\text { Recoleta }\end{array}$ & $\begin{array}{c}\text { La Granja } \\
\text { Quinta Normal }\end{array}$ \\
\hline Sindicatos & Recoleta & La Granja \\
\hline Juntas vecinales & Lo Espejo & $\begin{array}{c}\text { La Granja } \\
\text { Quinta Normal }\end{array}$ \\
\hline $\begin{array}{l}\text { Coleta de } \\
\text { assinaturas }\end{array}$ & Lo Espejo Granja \\
\hline $\begin{array}{l}\text { Manifestações ou } \\
\text { protestos }\end{array}$ & Lo Espejo & $\begin{array}{c}\text { Quinta Normal } \\
\text { Quinta Normal } \\
\text { Recoleta } \\
\text { La Granja }\end{array}$ \\
\hline Greves & & $\begin{array}{c}\text { Quinta Normal } \\
\text { Recoleta }\end{array}$ \\
\hline
\end{tabular}

Estes resultados evidenciam que Lo Espejo se destaca como sendo a comuna que tende a ser mais participativa, enquanto La Granja e Quinta Normal se destacam como as que tendem a ser menos participativas.

Coleta de assinaturas, manifestações ou protestos e greves apresentaram, também, relação com o nível educacional. Em coleta de 
assinaturas $^{14}$ a tendência é inversa: quanto maior o nível de escolaridade menor a participação. Em manifestações ou protestos ${ }^{15} e$ greves $^{16}$ são os respondentes de nível médio técnico completo e superior completo que tendem a ser mais ativos.

Para se ter idéia do número de atividades em que cada entrevistado declarou participar, fez-se uma contagem das respostas sim à participação em partidos políticos, reuniões políticas, atos públicos, associações comunitárias, associações religiosas, sindicatos, juntas vecinais, ONGs, coleta de assinaturas, manifestações ou protestos, greves, ocupação de terrenos ou edifícios públicos e outros, obtendo-se que $51,2 \%$ dos entrevistados não têm nenhum tipo de participação e $27,0 \%$ participam de somente um tipo de atividade e essa atividade, já sabemos, é principalmente a associação religiosa pois, como já foi visto anteriormente, 26,2\% declararam participar dessa atividade (veja figura 10).

O número mais alto de participação foi de uma única pessoa que declarou participar de 8 das atividades listadas. A média de participação $(0,97)$ não chegou a uma atividade por pessoa, evidenciando a baixa participação da população. A figura seguinte ilustra essa situação mostrando o percentual de pessoas dentro das categorias: 0 (nenhuma participação), 1 (participação em uma das atividades listadas), 2 (participação em duas das atividades listadas), 3 (participação em três das atividades listadas), etc.

\footnotetext{
${ }^{14}$ Qui-quadrado com 8 g.l. $=32,259$ e $p=0,001$.

${ }^{15}$ Qui-quadrado com 8 g.l. $=38,310$ e $p<0,001$.

${ }^{16}$ Qui-quadrado com 8 g.l. $=30,925$ e $p=0,002$.
} 
Figura 11. Percentual de entrevistados segundo o número de grupos em que participam

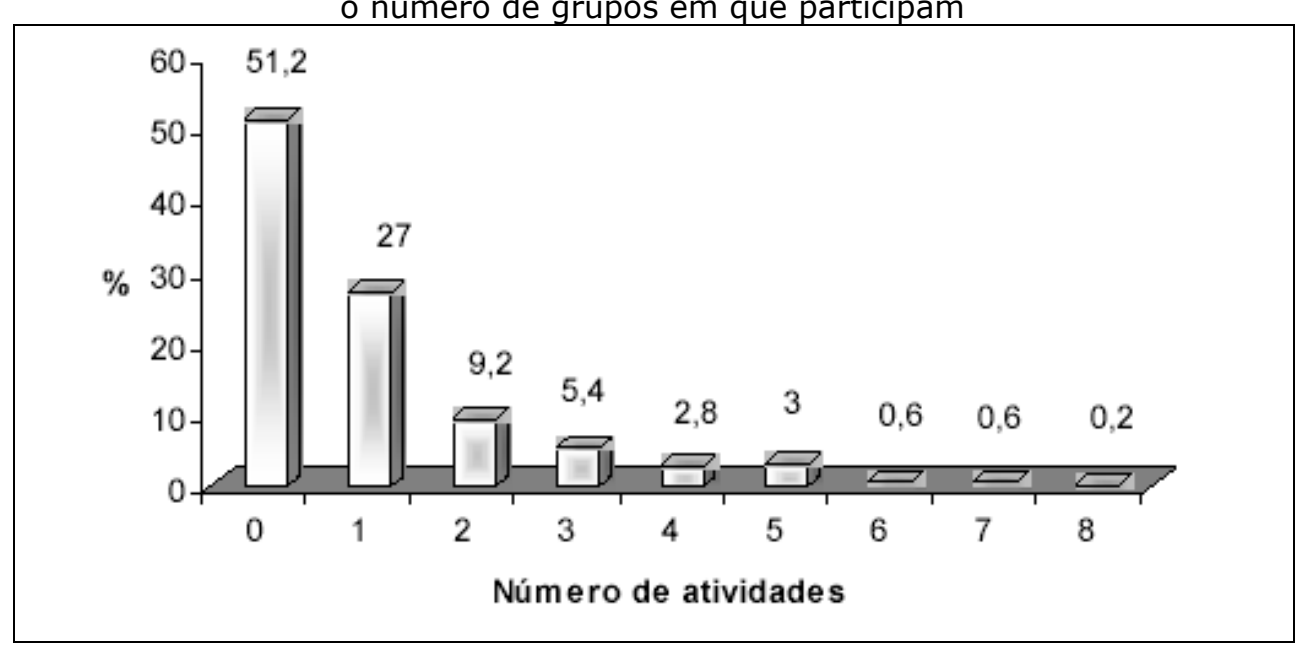

A baixa participação provavelmente decorre do fato de que a maioria das pessoas (56\%) não considera que sua participação política seja importante para solucionar problemas do país. Essa visão não tem relação com o sexo, nem com a idade e nem com a comuna do respondente. Entretanto há significativos $43 \%$ que consideram ser importante a sua participação na política e são provavelmente os que declararam ter algum tipo de participação.

Figura 12. Visão dos entrevistados sobre a importância de sua participação na política

\begin{tabular}{|l|l|}
\hline \multicolumn{2}{|c|}{ Você cons idera importante sua participação na política para } \\
solucionar os problemas do pais?
\end{tabular}


Como visto anteriormente, um dos mais baixos tipos de participação é a participação em partidos políticos (veja figura 10). Entretanto, essa pouca participação não é particularidade da população chilena. Observa-se que isso é uma realidade em vários países do mundo. Dados da Pesquisa World Values Survey revelam que a participação em partidos políticos é baixa tanto nos países ricos como nos países da América Latina. A figura seguinte apresenta os resultados de participação em partidos políticos, igreja, sindicatos e juntas vecinais obtidos nas pesquisa WVS para a França, Grã-Bretanha, Itália, Peru, Venezuela, Uruguai e Chile, além do resultado desta pesquisa e de outra realizada em Brasília ( $\mathrm{Br}$ ) em Santiago do Chile $(\mathrm{Cl})$ sobre a Identidade da Renovação Carismática Católica.

Tabela 7. Percentual de pessoas com participação ativa em Partidos políticos, Igreja, Sindicatos e Junta Vecinal

\begin{tabular}{|c|c|c|c|c|c|c|c|c|c|c|c|}
\hline Participação & \begin{tabular}{|c|} 
Chile \\
Wvs \\
1995 \\
\end{tabular} & $\begin{array}{l}\text { RCC } \\
\text { Stgo } \\
2004 \\
\end{array}$ & $\begin{array}{l}\text { Chile } \\
2005\end{array}$ & \begin{tabular}{|c|} 
RCC \\
BsB \\
2003 \\
\end{tabular} & $\begin{array}{c}\text { França } \\
\text { Vws }\end{array}$ & G.B. & $\begin{array}{c}\text { Alemanha } \\
\text { wvs }\end{array}$ & $\begin{array}{c}\text { Itália } \\
\text { wvs }\end{array}$ & $\begin{array}{l}\text { Peru } \\
\text { wvs }\end{array}$ & $\begin{array}{c}\text { Venezuela } \\
\text { wvs }\end{array}$ & $\begin{array}{c}\text { Uruguai } \\
\text { wVs }\end{array}$ \\
\hline $\begin{array}{l}\text { Partido } \\
\text { Político }\end{array}$ & 2,5 & 2,0 & 2,8 & 6,5 & 1,7 & 1,5 & 3,3 & 5,8 & 2,6 & 3,8 & 6,1 \\
\hline Igreja & 18,6 & 100,0 & 26,2 & 100,0 & 3,6 & 5,9 & 8,9 & 3,9 & 23,8 & 20,9 & 14,0 \\
\hline $\begin{array}{l}\text { Sindicato } \\
\text { Junta } \\
\text { vecinal* }\end{array}$ & $\begin{array}{l}3,4 \\
3,6\end{array}$ & $\begin{array}{r}5,1 \\
33,7\end{array}$ & $\begin{array}{l}1,8 \\
8,2\end{array}$ & $\begin{array}{l}28,4 \\
11,9\end{array}$ & $\begin{array}{l}2,6 \\
2,4\end{array}$ & $\begin{array}{r}1,2 \\
1,6\end{array}$ & $\begin{array}{l}2,8 \\
2,4\end{array}$ & $\begin{array}{l}3,1 \\
1,2\end{array}$ & $\begin{array}{l}4,2 \\
7,4\end{array}$ & $\begin{array}{l}5,2 \\
8,3\end{array}$ & 4,5 \\
\hline
\end{tabular}

* Na pesquisa do WVS não havia a categoria Junta Vecinal. Utilizou-se para a comparação a categoria associações.

Observa-se que a participação religiosa é a maior participação em quase todos os países, com exceção da Itália que apresentou maior participação em partidos políticos (5,8\%). Mesmo assim, esta participação ainda foi menor do que a participação dos membros da RCC de Brasília (6,5\%), que também apresentou a maior participação em sindicatos $(28,4 \%)$.

Observa-se também que a participação religiosa é muito baixa nos países europeus e relativamente alta nos países da América Latina. É também relativamente elevado o percentual de participação dos membros da RCC em junta vecinal, principalmente em Santiago $(33,7 \%)$. Aliás, a participação em juntas vecinales/associações também 
apresenta maior freqüência nos países latino-americanos. Para uma melhor visualização destes resultados veja-se a figura seguinte.

Figura 13. Participação em Partido político, Igreja, Sindicato e Junta vecinal por país

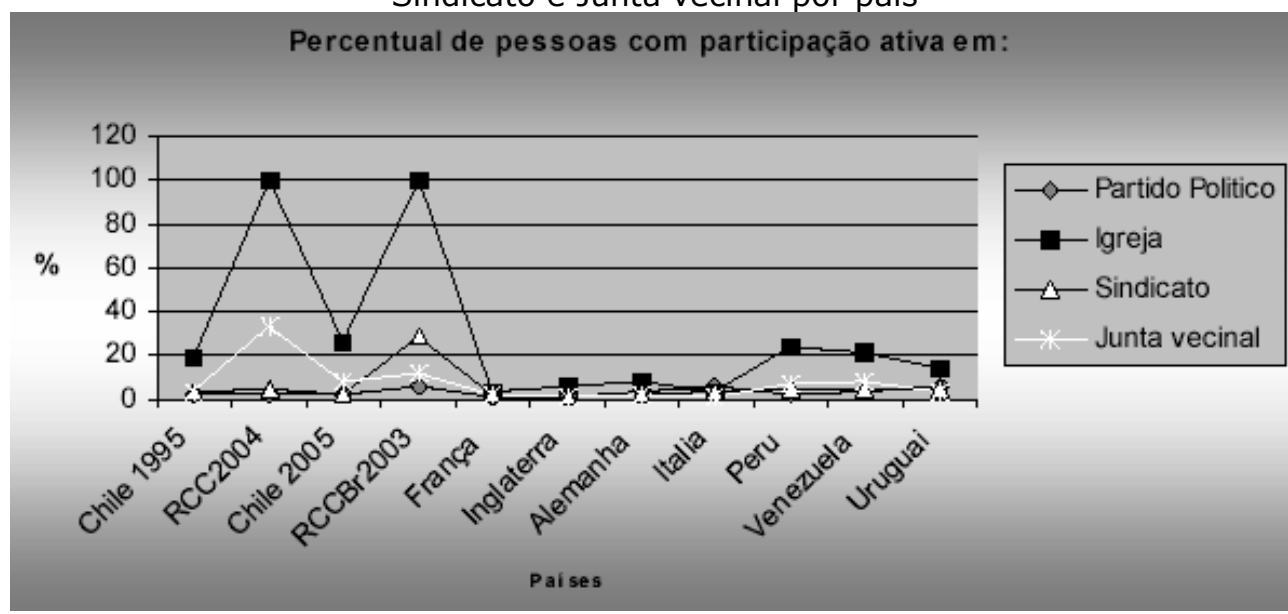

A comparação da participação com outros países pode ser melhor visualizada sem a presença da pesquisa sobre a RCC, como se vê na figura seguinte.

Figura 14. Participação em Partido político, Igreja, Sindicato e Junta vecinal por país, sem a presença da RCC

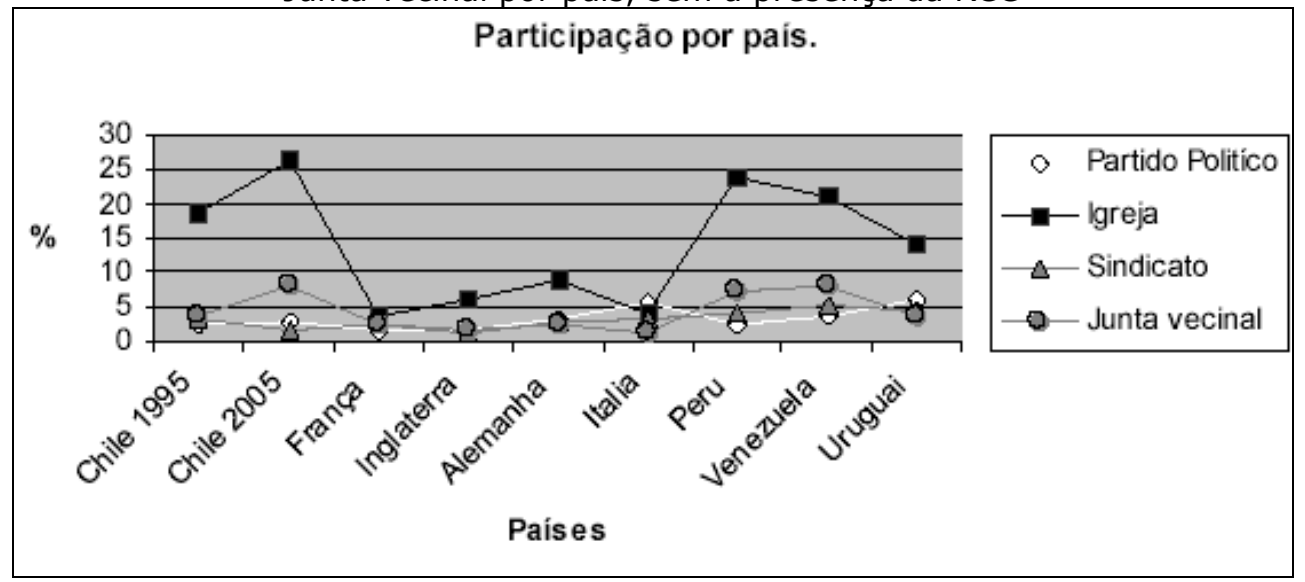

Uma coisa fica evidente nestes dados: a participação em partidos políticos e a participação em sindicatos são, com raras exceções, as que se apresentam mais baixas. 
Os entrevistados foram questionados sobre a existência de grupos que funcionavam em seu bairro como movimento político, associação cultural (arte, teatro, música, cinema), educacional (associação de pais e professores, reunião escolar), equipe esportiva, grupo de jovens, ONG ou grupo cívico (Cruz Vermelha), grupo baseado na comunidade étnica e grupos de mulheres.

Obteve-se que os grupos mais freqüentemente citados foram grupos esportivos $(77,6 \%)$ e de mulheres $(53,4 \%)$. Os grupos políticos $(18,6 \%)$, cívicos $(16,0 \%)$ e de comunidade étnica $(6,6 \%)$ foram os que apresentaram freqüência mais baixa. A tabela seguinte mostra esses resultados.

Tabela 8. Porcentagem de respostas que confirmam o funcionamento de grupos no bairro em que residem

\begin{tabular}{lc}
\hline \multicolumn{1}{c}{ Grupo } & $\%$ \\
\hline Esportivo & 77,6 \\
Jovens & 58,0 \\
Mulheres & 53,4 \\
Cultural & 49,6 \\
Educacional & 47,6 \\
Político & 18,6 \\
Cívico ou ONG & 16,0 \\
Comunidade étnica & 6,6 \\
\hline
\end{tabular}

Isso evidencia a preferência da população, que não privilegia movimentos políticos. O reconhecimento da existência ou não dos grupos movimento político ${ }^{17}$, associação cultural ${ }^{18}$, educacional ${ }^{19}$, equipe esportiva ${ }^{20}$, de jovens ${ }^{21}$, cívico ou ONGs $^{22}$ e mulheres ${ }^{23}$ apresentou relação de dependência com as comunas ${ }^{24}$.

Os respondentes de Lo Espejo tendem, mais do que o esperado, a dizer sim para a existência de todos os grupos apresentados,

\footnotetext{
${ }^{17}$ Qui-quadrado com 4 g.l. $=16,389$ e $p=0,003$.

${ }^{18}$ Qui-quadrado com 4 g.l. $=14,723$ e $p=0,005$.

${ }^{19}$ Qui-quadrado com 4 g.l. $=60,109$ e $p<0,000$.

${ }^{20}$ Qui-quadrado com 4 g.l. $=15,065$ e $p=0,005$.

${ }^{21}$ Qui-quadrado com 4 g.l. $=33,247$ e $p<0,000$.

${ }^{22}$ Qui-quadrado com 4 g.l. $=50,565$ e $p<0,000$.

${ }^{23}$ Qui-quadrado com 4 g.l. $=41,348$ e $p<0,000$.

${ }^{24}$ Para realização do teste do qui-quadrado eliminou-se as categorias NS e NR pelo baixo número de freqüência, o que dificulta a decisão do teste.
} 
apontando para uma maior participação dos moradores dessa comuna. A tabela seguinte mostra as tendências de cada comuna com os respectivos grupos:

Quadro 2. Relação das comunas com os diversos grupos

\begin{tabular}{|l|c|c|}
\hline \multicolumn{1}{|c|}{ Grupos } & $\begin{array}{c}\text { Comunas cujos moradores } \\
\text { tendem a admitir mais a } \\
\text { existência do grupo em seu } \\
\text { bairro }\end{array}$ & $\begin{array}{c}\text { Comunas cujos moradores } \\
\text { tendem a declarar mais que } \\
\text { o grupo não existe no seu } \\
\text { bairro }\end{array}$ \\
\hline $\begin{array}{l}\text { Movimento } \\
\text { político }\end{array}$ & Lo Espejo & $\begin{array}{c}\text { La Granja } \\
\text { Recoleta }\end{array}$ \\
\hline $\begin{array}{l}\text { Associações } \\
\text { culturais }\end{array}$ & Lo Espejo & Recoleta \\
\hline Educacional & Pedro Aguirre & La Granja \\
\hline $\begin{array}{l}\text { Equipe } \\
\text { Esportiva }\end{array}$ & Lo Espejo & Las Granja \\
\hline Jovens & Lo Espejo & La Granja \\
\hline $\begin{array}{l}\text { Cívico ou } \\
\text { ONGs }\end{array}$ & Pedro Aguirre & La Granja \\
\hline Mulheres & Lo Espejo & Recoleta \\
\hline & Quinta Normal & Lo Espejo \\
Recoleta & Pedro Aguirre \\
\hline
\end{tabular}

Se os moradores de Lo Espejo tendem a admitir mais que os outros a existência de todos esses grupos em seu bairro, os de La Granja, ao contrário, tendem a negar o funcionamento desses grupos na localidade em que vivem. Não foi detectada relação da variável comunidades étnicas com comuna.

Pedro Aguirre tende a destacar-se na existência dos grupos de jovens e culturais. Em Recoleta a tendência é admitir mais a existência de grupos de mulheres e negar a existência de associações culturais, equipe desportiva e ONGs.

Aos que responderam que não participavam de nenhum desses grupos questionou-se sobre a razão. A falta de tempo $(42,6 \%)$ e a falta de interesse $(41,4 \%)$ foram as razões mais freqüentemente apresentadas. Outras razões como motivos pessoais $(28,8 \%)$, falta de credibilidade $(25,6 \%)$ e não trazer benefícios(17,6\%) foram menos alegadas como motivo da não pertença. Todas essas razões estão fortemente relacionadas com a comuna ${ }^{25}$.

${ }^{25}$ Falta de tempo: qui-quadrado com 4 g.l. $=25,833$ e $p<0,001$. 
Tabela 9. Razões alegadas para a não participação em grupos

\begin{tabular}{lr}
\multicolumn{2}{c}{ Razões } \\
\hline Falta de tempo & $\mathbf{\%}$ \\
Falta de interesse & 42,6 \\
Falta de credibilidade & 41,4 \\
Não traz benefícios & 25,6 \\
Impossibilidade/motivos pessoais & 17,6 \\
Outro & 28,8 \\
\hline
\end{tabular}

As pessoas da comuna de Recoleta tendem a alegar, mais que as outras comunas, todas as razões acima mencionadas. Os respondentes de Lo Espejo tendem a privilegiar para a não participação falta de credibilidade, problemas pessoais e porque não traz benefícios. Os da comuna Pedro Aguirre tendem para a falta de credibilidade.

Aos que responderam que participavam de algum grupo, o motivo mais alegado foi de ordem espiritual, confirmando que a grande participação das pessoas é em atividade religiosa. O segundo motivo mais alegado é o prazer ou diversão.

Tabela 10. Razões alegadas para participação em grupos

\begin{tabular}{lc}
\hline \multicolumn{1}{c}{ Razões } & $\mathbf{\%}$ \\
\hline Melhorar o salário familiar ou acesso a serviços & 1,6 \\
É importante em situações de emergência no futuro & 0,4 \\
Traz benefícios para a comunidade & 5,0 \\
Prazer ou diversão & 9,6 \\
Espiritual, posição social, auto-estima & 12,0 \\
Outro & 1,8 \\
Não participam de grupos & 69,6 \\
\hline \multicolumn{1}{c}{ Total } & 100,0 \\
\hline
\end{tabular}

Os respondentes, em grande maioria, têm a percepção de que o bem-estar do chileno depende do esforço de cada um, mostrando a consciência que a população tem de sua própria responsabilidade na construção de uma vida melhor. Somente $33 \%$ consideram que seja o

Falta de interese: qui-quadrado com 4 g.l. $=16,722$ e $p=0,002$.

Falta de credibilidade: qui-quadrado com 4 g.l. $=31,521$ e $p<0,001$.

Não traz benefícios: qui-quadrado com 4 g.l. $=49,104$ e $p<0,001$.

Imposibilidade/motivos pessoais: qui-quadrado com $4 \mathrm{~g} . \mathrm{I} .=77,190$ e $\mathrm{p}<0,001$.

REVISTA DEBATES, Porto Alegre, v.1, n.1, p. 132-166, jul.-dez. 2007. 
Governo o responsável por esse bem-estar. A figura seguinte mostra essa realidade.

Figura 15. Opinião dos entrevistados sobre quem é o principal responsável pelo bem-estar do chileno

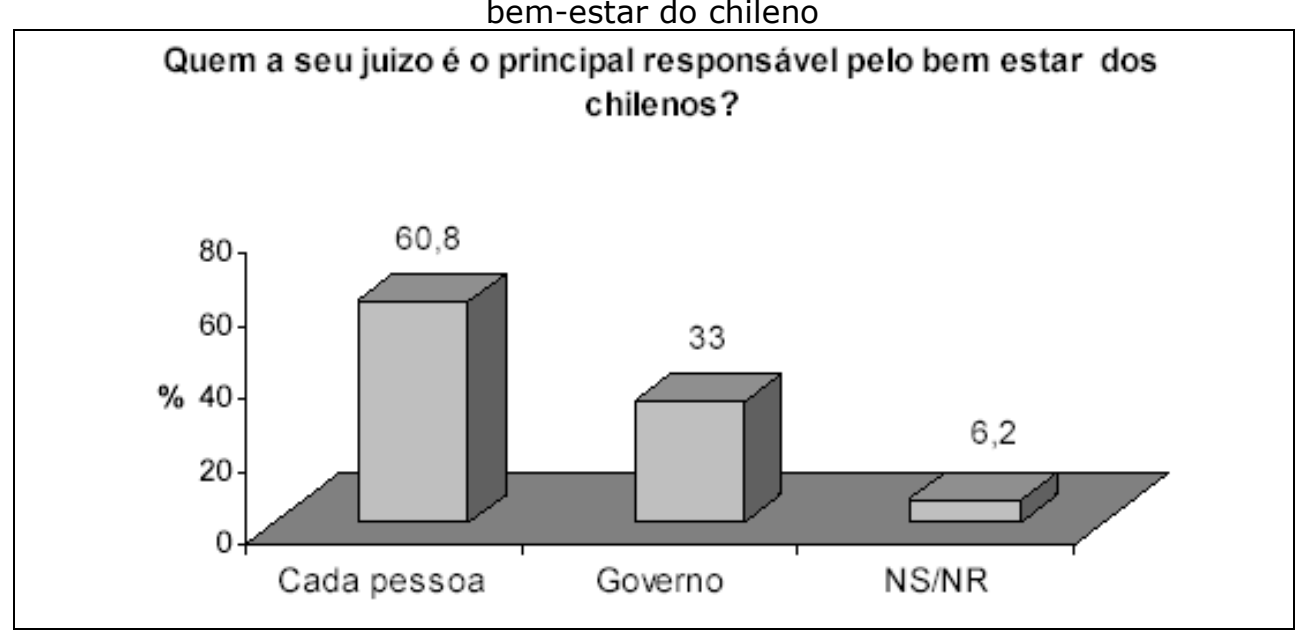

Se, por um lado, a maioria dos respondentes não se interessa por política $(57,0 \%)$ e não considera que sua participação política seja importante para resolver os problemas do país, por outro, $78,4 \%$ consideram que a colaboração entre as pessoas pode contribuir para melhorar a situação do país. Observa-se aqui um grande potencial de Capital Social.

Figura 16. Opinião sobre colaboração entre as pessoas

Em sua opinião a colaboração entre as pessoas pode contribuir para melhorar a situação do país?

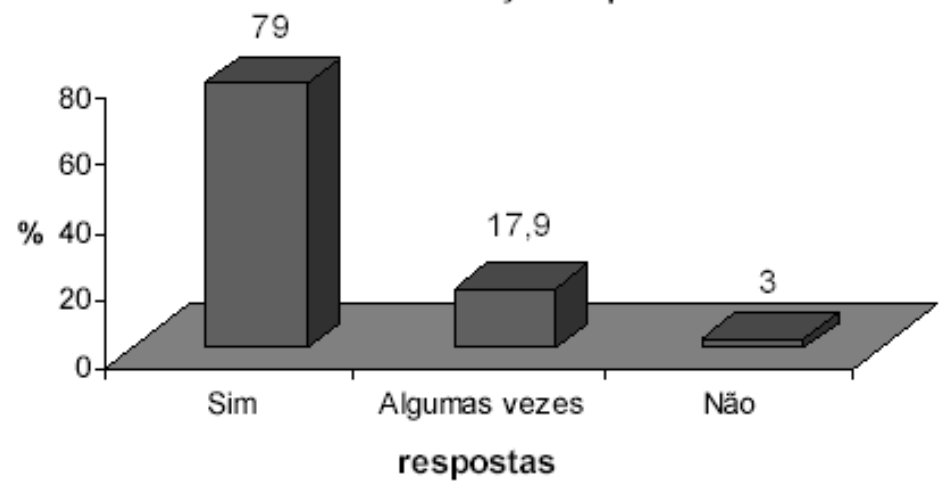


Essa idéia apresenta relação com a comuna ${ }^{26}$. Destacam-se como os que tendem a privilegiar a categoria sim os moradores da comuna Quinta Normal e, com menos intensidade, os da comuna La Granja, justamente as comunas que não privilegiaram a participação em nenhum dos grupos apresentados. Lo Espejo e Pedro Aguirre tendem a privilegiar a idéia de que a colaboração entre as pessoas não ajuda a melhorar a situação do país. É interessante notar que Lo Espejo foi a comuna que mais privilegiou a participação em grupos. Pedro Aguirre, apesar de ter privilegiado a participação no passado, também apresentou bastante tendência para a participação no presente e, no entanto, são justamente essas comunas que menos consideram a colaboração mútua. Observa-se algo como uma relação inversa entre participação e colaboração mútua.

O sexo também apresentou relação com a idéia de que a colaboração entre as pessoas contribui para melhorar a situação do país ${ }^{27}$. Os homens tendem a privilegiar a resposta sim e as mulheres, algumas vezes.

Entretanto, nem sempre as idéias são colocadas na prática e é isso que está claro quando $68,0 \%$ dos respondentes declaram que nunca trataram de solucionar algum problema local do bairro ou comunidade junto a outras pessoas.

Figura 17. Colaboração das pessoas em problemas locais

Nos últimos anos você tratou de solucionar algum problema local do bairro ou com unidade junto com outras pessoas?

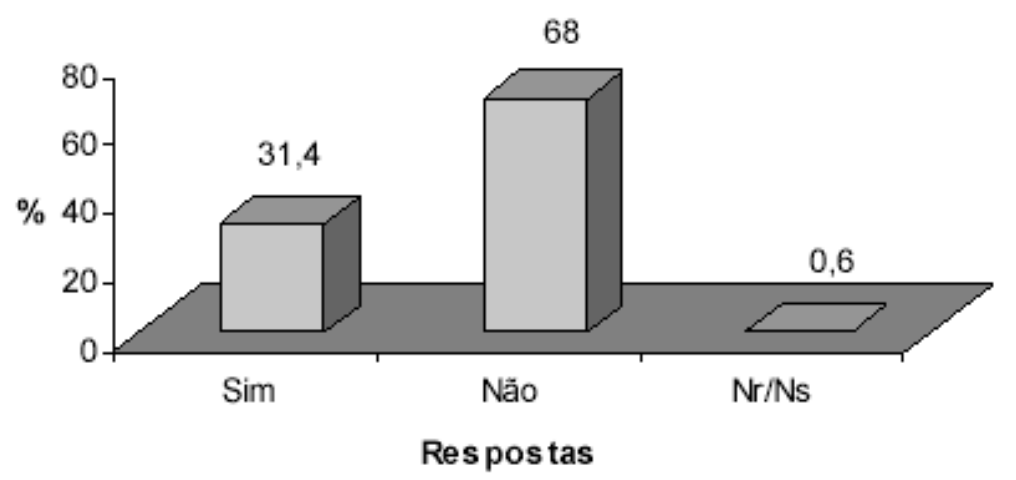

${ }^{26}$ Qui-quadrado com 8 g.l. $=18,499$ e $p=0,018$.

27 Qui-quadrado com 2 g.l. $=6,382$ e $p=0,041$. 
Esse resultado não apresentou relação com comunas, mas sim com o sexo ${ }^{28}$. Os homens tendem a responder mais sim que as mulheres, ou seja, eles tendem a participar mais do que elas em soluções de problemas na comunidade local.

Em relação à ajuda mútua, 55,6\% responderam que podem contar com vizinhos para ocupar-se de sua casa e de seus filhos caso necessitem viajar por um ou dois dias e 12,6\% consideram que é provável que recebam essa ajuda.

Tabela 11. Sobre ajuda mútua

\begin{tabular}{lc}
$\begin{array}{l}\text { No caso de necessitar viajar por um ou dois dias, } \\
\text { você poderia contar com os vizinhos para cuidar } \\
\text { de sua casa e/ou filhos? }\end{array}$ & $\%$ \\
\hline Sim & \\
Provavelmente & 55,6 \\
Não & 12,6 \\
NS-NR & 31,0 \\
\hline \multicolumn{2}{c}{ Total } \\
\hline
\end{tabular}

Essa ajuda mútua apresentou relação com comuna ${ }^{29}$. É a comuna La Granja que tende mais a responder sim, ou seja, é a que tende a considerar mais que receberá ajuda dos vizinhos. Isso é coerente com a idéia, também privilegiada por essa comuna, de que a colaboração mútua pode ajudar a melhorar a situação do país.

Em relação a uma situação de emergência como a enfermidade de um familiar ou perda de emprego, 84,4\% consideram que receberiam ajuda de familiares, $43,8 \%$ de vizinhos e $31,2 \%$ de companheiros de trabalho.

Mas, quando a pergunta é a maioria das pessoas do bairro geralmente se encontra disposta a ajudá-lo em caso de necessidade, somente $38,2 \%$ consideram que $\operatorname{sim}$ e $23,4 \%$ acham que nunca receberiam ajuda. Outros $32,8 \%$ pensam que receberiam ajuda algumas vezes e 5,6\% não souberam responder.

Mas o que chama a atenção é a falta de confiança uns nos outros. Mais da metade dos respondentes considera que é necessário

${ }^{28}$ Qui-quadrado com 1 g.l. $=15,411$ e $p<0,001$.

${ }^{29}$ Qui-quadrado com 8 g.l. $=15,795$ e $p=0,045$. 
estar atento porque as pessoas podem tirar vantagem (58,2\%) e 51,2\% não confiam nos outros para emprestar dinheiro. Somente $24,2 \%$ dos respondentes consideram que se pode confiar na maioria das pessoas que moram em seu bairro.

Tabela 12. Relacionamento com os vizinhos e pessoas do mesmo bairro

\begin{tabular}{lcccc}
\hline \multicolumn{1}{c}{ Perguntas } & Sim & $\begin{array}{c}\text { Algumas } \\
\text { vezes }\end{array}$ & Nunca & Ns-Nr \\
\hline $\begin{array}{l}\text { A maioria das pessoas do bairro geralmente } \\
\text { se encontra disposta a ajudá-lo em caso de } \\
\text { necessidade }\end{array}$ & 38,2 & 32,8 & 23,4 & 5,6 \\
$\begin{array}{l}\text { Se pode confiar na maioria das pessoas que } \\
\text { vivem no seu bairro }\end{array}$ & 24,2 & 42,4 & 31,8 & 1,6 \\
$\begin{array}{l}\text { Neste bairro é necessário estar atento porque } \\
\text { alguém pode tirar vantagem de você }\end{array}$ & 58,2 & 17,8 & 20,8 & 3,2 \\
$\begin{array}{l}\text { As pessoas do bairro em geral não confiam } \\
\text { umas nas outras para emprestar dinheiro }\end{array}$ & 51,2 & 10,2 & 26,2 & 12,4 \\
\hline
\end{tabular}

As respostas a estas quatro questões, independente do sexo das pessoas, apresentou forte relação com a comuna a que pertencem.

$\mathrm{Na}$ primeira questão, "A maioria das pessoas do bairro..." ${ }^{30}$, os respondentes da comuna Quinta Normal privilegiaram, mais do que o esperado, a resposta sim, ou seja, são eles que tendem a considerar mais que as pessoas do bairro estão dispostas a ajudá-los em caso de necessidade. La Granja está dividida entre sim e nunca, enquanto Recoleta e Lo Espejo privilegiam algumas vezes.

Na segunda questão, "Se pode confiar na maioria..."131, La Granja tende a considerar mais que as outras comunas que nunca se pode confiar nas pessoas do bairro, enquanto Quinta Normal tende a considerar que sim e Recoleta privilegia algumas vezes.

$\mathrm{Na}$ terceira, "Neste bairro é necessário estar atento..."32, é a comuna La Granja que tende a privilegiar o sim, ou seja, são os que mais consideram que se deve estar atento porque alguém pode tirar vantagem. Por outro lado, as pessoas das comunas Quinta Normal e Pedro Aguirre tendem a privilegiar a resposta nunca.

\footnotetext{
${ }^{30}$ Qui-quadrado com 8 g.l. $=30,576$ e $p<0,001$.

${ }^{31}$ Qui-quadrado com $8 \mathrm{~g} . \mathrm{l} .=80,441$ e $\mathrm{p}<0,001$.

32 Qui-quadrado com 8 g.l. $=27,436$ e $p=0,001$.
} 
Finalmente, na questão "As pessoas do bairro em geral não confiam umas nas outras para emprestar dinheiro" ${ }^{\prime 33}$, as comunas La Granja, Pedro Aguirre e Recoleta tendem a privilegiar a resposta sim mais que as outras significando que, em geral, não confiam nas pessoas para emprestar dinheiro. Ao mesmo tempo, a comuna Lo Espejo privilegiou a resposta nunca, ou seja, seus membros confiam uns nos outros para emprestar dinheiro.

Estes resultados demonstram que, de uma maneira geral, as pessoas de La Granja são mais desconfiadas que as das outras comunas.

\section{Falando do Chile}

A preservação do meio ambiente é tema muito discutido na conjuntura atual. A utilização indiscriminada dos recursos naturais e a contaminação do meio ambiente têm preocupado os estudiosos do assunto. Questiona-se quem é o principal responsável pela série de problemas provenientes dessas atitudes pouco preventivas.

Indagados sobre quem seria o principal responsável pela poluição atmosférica, que acarreta uma série de problemas ambientais e de saúde no Chile, os entrevistados, em sua maioria $(37,0 \%)$, consideram que são as empresas as principais responsáveis por essa poluição, enquanto $28,8 \%$ consideram que são os transportes públicos e $16,2 \%$ responsabilizam o governo. A figura seguinte mostra estes resultados.

Figura 18. Opinião dos entrevistados sobre quem é o principal responsável pela poluição atmosférica

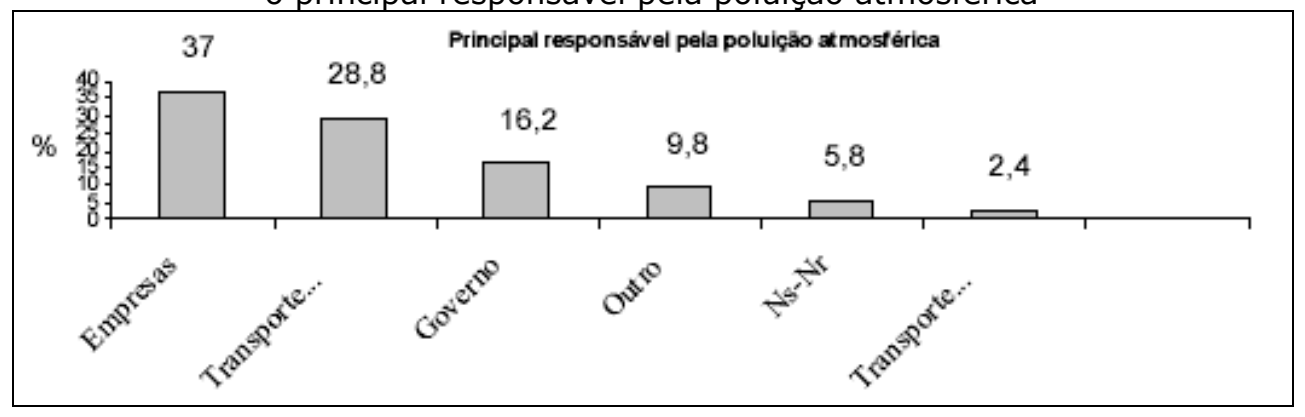

${ }^{33}$ Qui-quadrado com 8 g.l. $=189,748$ e $p<0,001$. 
Essas opiniões estão relacionadas com a comuna ${ }^{34}$. Os entrevistados de La Granja tendem a responsabilizar mais o transporte público, enquanto os de Lo Espejo, o governo. Por outro lado, os de Quinta Normal e Recoleta, as empresas.

Os entrevistados revelam visão positiva em relação às oportunidades que têm em comparação com as de seus pais. A maioria, $57,4 \%$, considera que hoje as oportunidades de ter um melhor nível de vida são maiores do que as de seus pais. Os outros se dividem em considerar que as oportunidades são iguais $(20,6 \%)$ ou que são menores (21,0\%). Um reduzido percentual de $1,0 \%$ não respondeu.

Essa visão positiva continua em relação ao futuro, ou seja, $63,8 \%$ consideram que as chances que as crianças e os jovens de hoje têm de melhorar o nível de sua vida também são maiores. O percentual dos que consideram que as oportunidades permanecerão as mesmas cai para $18,6 \%$ e menor ainda é a porcentagem dos que acham que as oportunidades são menores (14,0\%). A figura seguinte evidencia essa visão otimista em relação ao futuro.

Figura 19. Percepção dos entrevistados quanto às oportunidades dos filhos em comparação aos pais e ao futuro

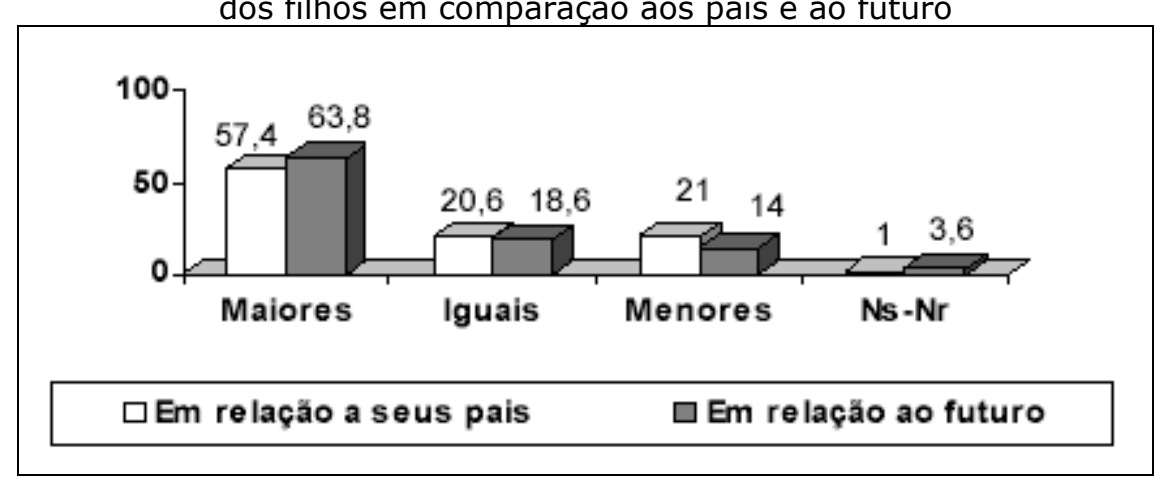

De maneira geral o entrevistado se sente feliz (70,6\%), satisfeito $(66,2 \%)$, realizado $(67,2 \%)$ e seguro $(51,8 \%)$ na sociedade chilena, mas, $23,0 \%$ declaram que se sentem infelizes, $32,0 \%$ estão insatisfeitos, $28,6 \%$ sentem-se frustrados e $46,2 \%$, inseguros.

${ }^{34}$ Qui-quadrado com 16 g.l. $=45,455$ e $p<0,001$. 
Mas quem são as pessoas que mais sentem os sentimentos negativos ou os positivos? Foi detectada relação de dependência desses sentimentos com a comuna ${ }^{35}$ e somente o item segurança não apresentou tal relação. O que significa que não há diferença significativa entre as comunas no que tange a sentir-se seguro ou inseguro. Em compensação, o sentimento de segurança foi o único que apresentou relação com o sexo ${ }^{36}$. Os homens sentem-se mais seguros que as mulheres. Este é um resultado esperado considerando que tradicionalmente o homem tem sido o protetor da mulher. Embora essa realidade esteja mudando, a sociedade ainda carrega muito dessa tradição.

Em relação ao sentimento de felicidade, destacam-se os entrevistados de Recoleta como sendo os que tendem a se sentir felizes, enquanto os de Lo Espejo tendem a sentir-se infelizes. Recoleta também se destaca como sendo a comuna em que seus membros tendem a sentir-se mais satisfeitos e realizados. Em relação ao sentimento de realização, o resultado do teste ficou um pouco indefinido por cair em uma zona limite, dificultando a decisão. Entretanto, a análise dos dados deixa evidente a tendência de Recoleta para o sentimento de realização, enquanto Lo Espejo tende ao sentimento de frustração.

Para uma melhor visualização dos sentimentos relacionados com as comunas, o quadro seguinte sintetiza esses resultados.

Quadro 3. Relação de Sentimentos com comuna

\begin{tabular}{|l|c|c|}
\hline \multicolumn{1}{|c|}{ Sentimentos } & $\begin{array}{c}\text { Comunas que } \\
\text { tendem a responder } \\
\text { mais Sim do que o } \\
\text { esperado }\end{array}$ & $\begin{array}{c}\text { Comunas que tendem a } \\
\text { responder mais Não em } \\
\text { relação ao esperado }\end{array}$ \\
\hline Feliz (Sim)/Infeliz (Não) & Recoleta & Lo Espejo \\
\hline Satisfeito (Sim)/Insatisfeito(Não) & Recoleta & $\begin{array}{c}\text { Lo Espejo } \\
\text { Pedro Aguirre }\end{array}$ \\
\hline Realizado (Sim)/Frustrado (Não) & $\begin{array}{c}\text { Recoleta } \\
\text { Quinta Normal }\end{array}$ & Lo Espejo \\
\hline
\end{tabular}

\footnotetext{
35 Para felicidade: Qui-quadrado com $4 \mathrm{~g} . \mathrm{I} .=18,116$ e $\mathrm{p}=0,001$ Para satisfação: Qui-quadrado com $4 \mathrm{~g} . \mathrm{I}=11,565$ e $\mathrm{p}=0,021$. Para realização: Qui-quadrado com 4 g.l. $=9,539$ e $p=0,049$.

${ }^{36}$ Qui-quadrado com 1 g.l. $=10,581$ e $p=0,001$.
} 
Estes resultados nos revelam que na comuna Recoleta há maior predisposição para os sentimentos positivos de felicidade, satisfação e realização, enquanto na comuna Lo Espejo há maior predisposição para os sentimentos de infelicidade, insatisfação e frustração.

A idade também influi nos sentimentos de satisfação ${ }^{37}$, realização ${ }^{38}$ e segurança ${ }^{39}$. As pessoas com mais de 50 anos tendem a se sentir mais satisfeitas e realizadas do que as com menos de 50 anos. Isso é compreensível considerando que com esta idade já se está estabelecido na vida, enquanto os mais jovens ainda estão buscando realizar seus sonhos.

Em relação à segurança, são as pessoas com mais de 75 anos que tendem a se sentir mais seguras.

Em relação à dificuldade de pagar ou adquirir bens, a maioria dos entrevistados não encontra dificuldade para pagar ou obter alimentação $(50,6 \%)$, medicamentos $(46,2 \%)$, luz $(51,6 \%)$, água $(53,0 \%)$, vestimenta $(50,6 \%)$, transporte $(51,8 \%)$, telefonia $(48,2 \%)$, moradia $(66,6 \%)$ e acesso à Justiça $(61,2 \%)$. Observa-se na tabela seguinte que telefonia é o item que apresenta maior percentual de pessoas que encontram dificuldades para pagar ou adquirir o bem. A moradia foi o que apresentou o menor percentual de dificuldade, indicando que este não é o principal problema da população.

Tabela 13. Distribuição, em percentual, das respostas aos seguintes itens

\begin{tabular}{lcccc}
\hline $\begin{array}{c}\text { Em geral, você teve ou tem } \\
\text { dificuldades } \\
\text { para pagar ou obter }\end{array}$ & Sim & Algumas vezes & Não & Ns-Nr \\
\hline Alimentação & 13,4 & 36,0 & 50,6 & 0,0 \\
Medicamentos & 16,8 & 36,8 & 46,2 & 0,2 \\
Luz & 17,4 & 31,0 & 51,6 & 0,0 \\
Água & 16,8 & 30,2 & 53,0 & 0,0 \\
Vestimenta & 17,4 & 31,8 & 50,6 & 0,2 \\
Transporte & 17,2 & 30,6 & 51,8 & 0,4 \\
Telefonia & 20,8 & 26,8 & 48,2 & 4,2 \\
Moradia & 13,0 & 17,4 & 66,6 & 3,0 \\
Acesso à Justiça & 14,2 & 10,0 & 61,2 & 14,6 \\
\hline
\end{tabular}

${ }^{37}$ Qui-quadrado com 3g.l. $=9,838$ e $p=0,020$.

${ }^{38}$ Qui-quadrado com 3 g.l. $=10,319$ e $p=0,016$

${ }^{39}$ Qui-quadrado com 3 g.I. $=9,346$ e $p=0,025$. 
A figura seguinte dá uma visão geral da distribuição das respostas, evidenciando que a não dificuldade (Não) é a resposta mais freqüente.

Figura 20. Percentual de entrevistados segundo a dificuldade de pagar ou obter os seguintes itens

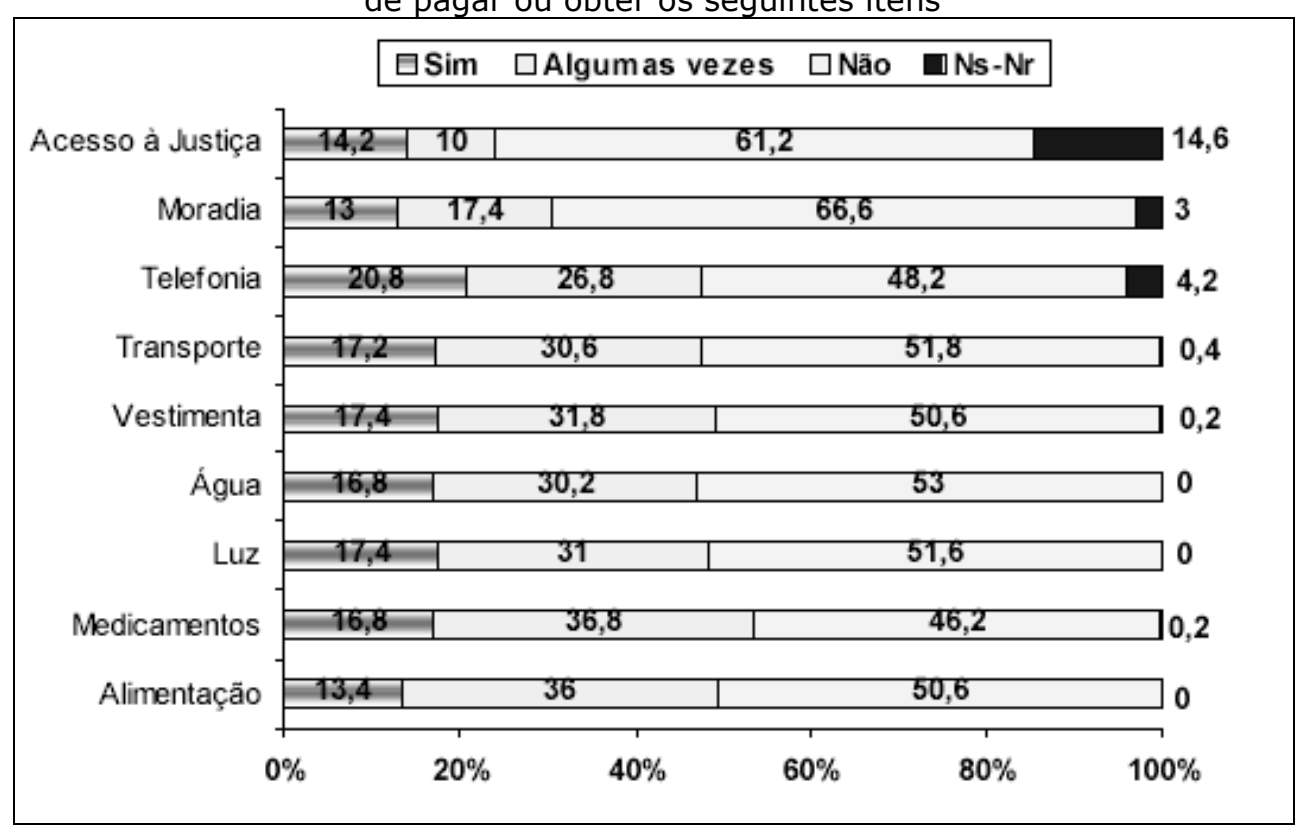

Mas quem são essas pessoas que declararam ter dificuldades em pagar ou obter esses bens? Em primeiro lugar, são as pessoas de baixa renda familiar. Para todos os itens, as pessoas que tendem mais a responder que têm dificuldade são as que têm renda familiar abaixo de 200.000 pesos, com exceção dos itens alimentação e moradia, em que a faixa de renda das com mais dificuldade cai para 100.000 pesos.

Mas quem são essas pessoas que ganham tão pouco e têm dificuldade de adquirir esses bens necessários para a vida cotidiana? Grande parte delas são as mulheres. Não exatamente por serem mulheres, mas por ganharem menos que os homens. O sexo apresentou forte relação de dependência com a renda familiar ${ }^{40}$. As mulheres tendem a se concentrar na faixa de renda até 200.000 pesos, enquanto os homens tendem a ganhar mais de 200.000 pesos. Este é o valor que

${ }^{40}$ Qui-quadrado com 6 g.l. $=15,293$ e $p=0,018$ 
marca a linha divisória de quando as pessoas tendem a sentir dificuldade de pagar ou obter os bens. A partir deste limite de renda as coisas começam a ser menos difíceis.

Outro fator que influi nesta dificuldade é o nível educacional, que também está fortemente relacionado com a renda familiar ${ }^{41}$. São as pessoas com baixo nível educacional, ou seja, as pessoas com até o ensino básico completo que mais tendem a sentir dificuldade para a obtenção dos bens. A partir do nível médio as pessoas tendem a ter menos dificuldade à medida que o grau de instrução aumenta.

A idade também apresentou relação com alguns itens. Com luz, água, vestimenta, transporte, telefonia, moradia ela não apresentou relação, mas com alimentação ${ }^{42}$ e medicamentos ${ }^{43}$, sim, e são as pessoas com mais de 50 anos que tendem a ter mais dificuldade de adquirir ou pagar o bem. Isso é compreensível considerando que os idosos são os que necessitam de maiores cuidados e têm maiores gastos com saúde. E a alimentação faz parte de um projeto de boa saúde. Para moradia e acesso à Justiça, a faixa de idade que tende a ter mais dificuldade é a de 26 a 50 anos. O que é compreensível no caso de moradia porque é nesta faixa de idade que as pessoas estão buscando realizar o sonho da casa própria.

Outro fator que marcou diferença nessas dificuldades foram as comunas. Para uma melhor compreensão dos resultados, o quadro seguinte apresenta as comunas cujas pessoas tendem a ter mais dificuldade e mais facilidade para pagar ou adquirir alimentação ${ }^{44}$, luz ${ }^{45}$, água ${ }^{46}$, vestimenta ${ }^{47}$, transporte ${ }^{48}$, moradia $^{49}$ e acesso à Justiça ${ }^{50}$.

\footnotetext{
${ }^{41}$ Qui-quadrado com 16. g.I. e $\mathrm{p}<0,001$. Para testar esta relação a variável renda familiar foi recodificada grupando-se os níveis mais altos de renda em uma única classe mais de 500.000 devido ao baixo número de respondentes que ganham acima deste valor.

42 Qui-quadrado com 6 g.l. $=16,431$ e $p=0,012$.

${ }^{43}$ Qui-quadrado com 6 g.l. $=13,933$ e $p=0,030$.

${ }^{44}$ Qui-quadrado com $8 \mathrm{~g} . \mathrm{l} .=24,143$ e $\mathrm{p}=0,002$.

${ }^{45}$ Qui-quadrado com 8 g.l. $=25,108$ e $p=0,001$.

${ }^{46}$ Qui-quadrado com 8 g.l. $=31,921$ e $p<0,001$.

47 Qui-quadrado com 8 g.l. $=40,086$ e $p<0,001$.

${ }^{48}$ Qui-quadrado com 8 g.l. $=23,129$ e $p=0,003$.

${ }^{49}$ Qui-quadrado com $8 \mathrm{~g} . \mathrm{l} .=16,745$ e $\mathrm{p}=0,033$.

50 Qui-quadrado com 8 g.l. $=50,401$ e $p<0,001$.
} 
Medicamentos e telefonia não apresentaram relação de dependência com a comuna.

Quadro 4. Relação de comuna com a facilidade ou dificuldade de adquirir ou pagar os itens seguintes

\begin{tabular}{|l|c|c|}
\hline $\begin{array}{c}\text { Itens } \\
\text { pesquisados }\end{array}$ & $\begin{array}{r}\text { Comunas cujas respostas } \\
\text { tenderam mais para Não, } \\
\text { ou seja, não encontram } \\
\text { dificuldade em pagar ou } \\
\text { adquirir os referidos itens }\end{array}$ & $\begin{array}{r}\text { Comunas cujas respostas } \\
\text { tenderam para Sim, ou seja, } \\
\text { as pessoas alegam ter } \\
\text { dificuldade de pagar ou } \\
\text { adquirir os referidos itens. }\end{array}$ \\
\hline Alimentação & La Granja & $\begin{array}{c}\text { Lo Espejo } \\
\text { Quinta Normal }\end{array}$ \\
\hline Luz & $\begin{array}{r}\text { La Granja } \\
\text { Pedro Aguirre } \\
\text { Recoleta }\end{array}$ & $\begin{array}{c}\text { Quinta Normal } \\
\text { Lo Espejo }\end{array}$ \\
\hline Água & $\begin{array}{r}\text { La Granja } \\
\text { Pedro Aguirre } \\
\text { Recoleta }\end{array}$ & $\begin{array}{c}\text { Lo Espejo } \\
\text { Pedro Aguirre } \\
\text { Quinta Normal }\end{array}$ \\
\hline Vestimenta & $\begin{array}{r}\text { La Granja } \\
\text { Recoleta }\end{array}$ & Pedro Aguirre \\
\hline Transporte & Recoleta & Lo Espejo \\
\hline Moradia & Pedro Aguirre \\
Recoleta & La Granja & Lo Espejo \\
\hline $\begin{array}{l}\text { Acesso à } \\
\text { Justiça }\end{array}$ & Pedro Aguirre &
\end{tabular}

Este quadro é bastante revelador. Observa-se que algumas comunas transitam da tendência a ter mais facilidade em alguns itens para mais dificuldade em outros itens, como é o caso de Pedro Aguirre, cujos moradores têm mais dificuldade na vestimenta e no transporte, e mais facilidade em pagar ou obter luz, água, moradia e acesso à Justiça.

Outras tendem somente para a dificuldade ou para a facilidade, entre elas se destaca Lo Espejo, onde os moradores alegam encontrar dificuldade em todos os itens que apresentaram relação de dependência com as comunas.

Quinta Normal também apresentou tendência apenas para a dificuldade, mas não em todos os itens, somente para alimentação, luz e vestimenta.

Por outro lado, as comunas La Granja e Recoleta surgem como aquelas em que seus moradores apresentam tendência a não ter dificuldade no pagamento ou obtenção de quase todos os itens. 
Estes resultados apontam para uma melhor condição de vida nas comunas La Granja e Recoleta e uma pior condição em Lo Espejo. Como não há relação de dependência da variável comuna com renda familiar, nem educação, nem sexo, algo está provocando essas diferenças.

Estes resultados são coerentes com os encontrados no Quadro 3, sobre os sentimentos que predominam em determinadas comunas, destacando-se justamente Lo Espejo como a comuna em que aparece uma maior predisposição para os sentimentos de infelicidade, insatisfação e frustração, provavelmente ligados à maior dificuldade que essas pessoas encontram na vida. Por outro lado, é justamente Recoleta que se destaca como a comuna que apresenta maior predisposição para os sentimentos positivos de felicidade, satisfação e realização, provavelmente também ligados com a maior facilidade que há na vida dessas pessoas.

Novamente levanta-se a questão: se não há diferença significativa na renda familiar e na educação das pessoas dessas comunas, o que está facilitando ou dificultando a vida delas?

\section{Confiança}

De uma maneira geral, a confiança não parece ser a ênfase da população pesquisada, pois $74,2 \%$ consideram que, geralmente, não se pode confiar nas pessoas. Isso é uma questão generalizada, não apresentando relação de dependência com o sexo nem com as comunas.

Questionados quanto à confiança que depositam em algumas instituições da sociedade, os respondentes deixaram claro que as instituições que mais merecem a sua confiança são a família $(89,8 \%)$ e a Igreja (50,2\%). Os que mais angariam a desconfiança da população são os partidos políticos $(61,6 \%)$ e os sindicatos $(45,2 \%)$, explicando assim a pouca participação das pessoas nestas duas instituições. 
Tabela 14. Confiança nas instituições

\begin{tabular}{lcccc}
\hline Itens & Confia muito & Confia pouco & Não confia & Ns-Nr \\
\hline Congresso Nacional & 4,2 & 54,2 & 40,0 & 1,6 \\
Governo & 16,4 & 54,4 & 28,8 & 0,4 \\
Junta de vecinos & 11,8 & 39,4 & 43,8 & 5,0 \\
Municipalidade & 12,2 & 51,4 & 35,0 & 1,4 \\
Poder Judicial & 9,0 & 45,4 & 44,2 & 1,4 \\
Partidos políticos & 2,6 & 34,6 & 61,6 & 1,2 \\
Polícia & 19,4 & 56,8 & 23,6 & 0,2 \\
Igreja & 50,2 & 30,8 & 18,2 & 0,8 \\
Família & 89,8 & 8,2 & 1,8 & 0,2 \\
Vizinhos & 28,8 & 48,2 & 21,4 & 1,6 \\
Associações comunitárias & 12,4 & 49,8 & 31,8 & 6,0 \\
Sindicatos & 9,4 & 35,8 & 45,2 & 9,6 \\
Meios de comunicação & 21,2 & 51,4 & 26,6 & 0,8 \\
\hline
\end{tabular}

A figura seguinte evidencia que, de uma forma geral, é a pouca confiança que predomina e, em alguns casos, a desconfiança.

Figura 21. Confiança nas instituições

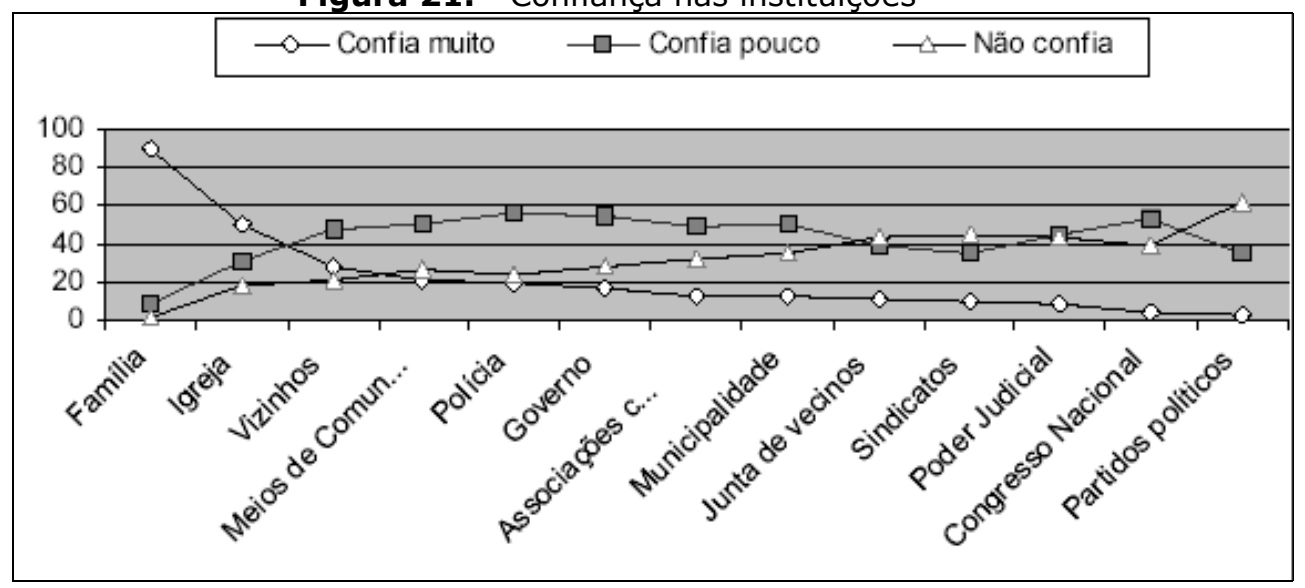

O sentimento de confiança apresentou relação de dependência com os itens Congresso Nacional ${ }^{51}$, Governo ${ }^{52}$, Municipalidade ${ }^{53}$, Poder Judiciário ${ }^{54}$, Partidos Políticos ${ }^{55}$, Polícia ${ }^{56}$, Igreja ${ }^{57}$, Família ${ }^{58}$, Associações

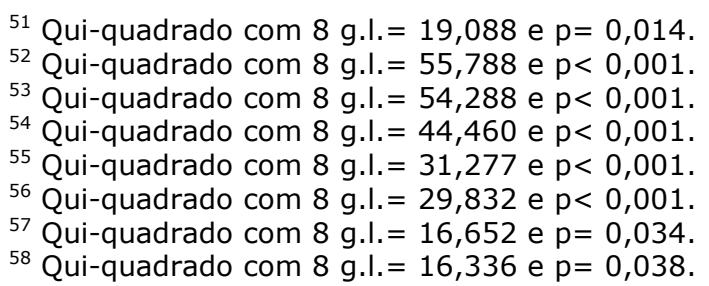


Comunitárias $^{59}$, Sindicatos ${ }^{60}$ e Meios de Comunicação ${ }^{61}$. Os itens Junta de vecinos e vizinhos não apresentaram relação com comuna, ou seja, não há diferença significativa na confiança que as pessoas das diferentes comunas dedicam a esses grupos. O quadro seguinte mostra essas tendências.

Quadro 5. Confiança nas instituições

\begin{tabular}{|c|c|c|c|}
\hline Itens & $\begin{array}{c}\text { Comunas que } \\
\text { tendem a } \\
\text { confiar }\end{array}$ & $\begin{array}{c}\text { Comunas que } \\
\text { tendem a confiar } \\
\text { pouco }\end{array}$ & $\begin{array}{c}\text { Comunas que } \\
\text { tendem a não } \\
\text { confiar }\end{array}$ \\
\hline \begin{tabular}{|l|} 
Congresso \\
Nacional \\
\end{tabular} & & $\begin{array}{c}\text { Pedro Aguirre } \\
\text { Recoleta }\end{array}$ & \\
\hline Governo & La Granja & $\begin{array}{c}\text { Pedro Aguirre } \\
\text { Recoleta }\end{array}$ & Quinta Normal \\
\hline Municipalidade & La Granja & Recoleta & $\begin{array}{l}\text { Lo Espejo } \\
\text { Quinta Normal }\end{array}$ \\
\hline Poder Judiciário & Lo Espejo & & Quinta Normal \\
\hline Partidos Políticos & $\begin{array}{l}\text { Lo Espejo } \\
\text { Recoleta }\end{array}$ & & $\begin{array}{c}\text { Quinta Normal } \\
\text { La Granja }\end{array}$ \\
\hline Polícia & $\begin{array}{l}\text { Lo Espejo } \\
\text { Recoleta }\end{array}$ & & Quinta Normal \\
\hline Igreja & $\begin{array}{l}\text { Lo Espejo } \\
\text { La Granja }\end{array}$ & Recoleta & $\begin{array}{l}\text { Pedro Aguirre } \\
\text { Quinta Normal }\end{array}$ \\
\hline Família & La Granja & Quinta Normal & Pedro Aguirre \\
\hline $\begin{array}{l}\text { Associações } \\
\text { Comunitárias } \\
\end{array}$ & Pedro Aguirre & $\begin{array}{l}\text { La Granja } \\
\text { Recoleta }\end{array}$ & $\begin{array}{c}\text { Lo Espejo } \\
\text { Quinta Normal }\end{array}$ \\
\hline \begin{tabular}{|l|} 
Sindicatos \\
\end{tabular} & Lo Espejo & Recoleta & Quinta Normal \\
\hline $\begin{array}{l}\text { Meios de } \\
\text { Comunicação }\end{array}$ & $\begin{array}{l}\text { Lo Espejo } \\
\text { La Granja }\end{array}$ & Recoleta & Quinta Normal \\
\hline
\end{tabular}

Observa-se aqui a tendência das comunas. Lo Espejo tende a confiar mais no Poder Judiciário, nos Partidos Políticos, na Polícia, na Igreja, nos Sindicatos e nos Meios de Comunicação revelando seu lado participativo na política emancipatória, enquanto Quinta Normal tende a desconfiar de, praticamente, todos os grupos referenciados. Recoleta destaca-se por confiar pouco em grande parte dos itens apresentados.

A onda de 1995 da Pesquisa Mundial de Valores (WVS) abordou o nível de confiança para instituições. Os resultados referentes ao Chile estão na tabela seguinte.

\footnotetext{
${ }^{59}$ Qui-quadrado com 8 g.l. $=40,055$ e $p<0,001$.

${ }^{60}$ Qui-quadrado com $8 \mathrm{~g} . \mathrm{l} .=35,207$ e $\mathrm{p}<0,001$

${ }^{61}$ Qui-quadrado com 8 g.l. $=36,403$ e $p<0,001$.
} 
Tabela 15. Confiança nas instituições resultados do WVS para o Chile- 1995 (\%)

\begin{tabular}{lcccc}
\hline \multicolumn{1}{c}{ Itens } & $\begin{array}{c}\text { Confia } \\
\text { muito }\end{array}$ & $\begin{array}{c}\text { Confia } \\
\text { razoavelmente }\end{array}$ & $\begin{array}{c}\text { Confia } \\
\text { pouco }\end{array}$ & Não confia \\
\hline Congresso & & & & \\
Nacional & 18,8 & 34,7 & 31,9 & 14,6 \\
Governo & 17,2 & 34,1 & 34,7 & 14,0 \\
Imprensa & 13,6 & 32,5 & 41,6 & 12,3 \\
TV & 7,6 & 51,2 & 29,2 & 12,0 \\
Partidos & & & & \\
políticos & 3,9 & 20,5 & 37,0 & 38,7 \\
Polícia & 22,2 & 33,6 & 31,1 & 13,0 \\
Igreja & 48,6 & 28,9 & 17,9 & 4,5 \\
Sindicatos & 17,4 & 29,1 & 37,7 & 15,9 \\
\hline
\end{tabular}

Os dados revelam que a Igreja é a que mais angaria a confiança dos chilenos, confirmando os resultados deste trabalho onde a Igreja só perde para a família. Destaca-se também a pouca confiança depositada nos partidos políticos.

Figura 22. Confiança nas instituições- Pesquisa WVS- Chile 1995

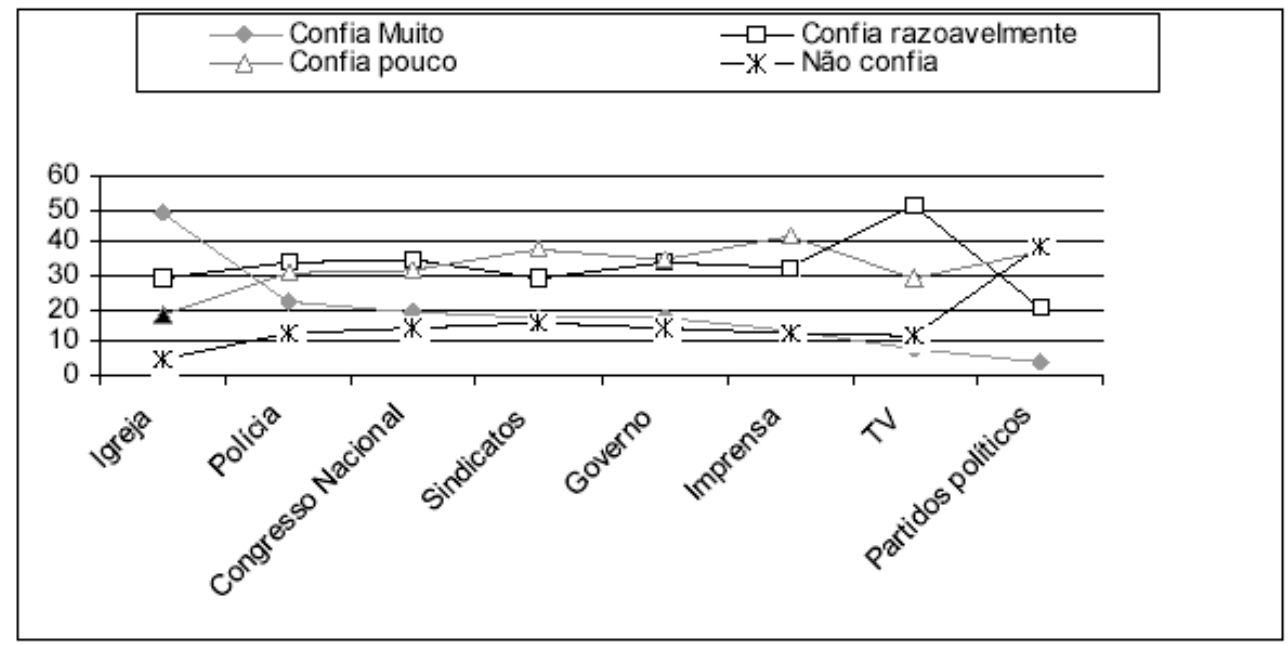

Embora não se possa comparar estes resultados por estarem em escalas diferentes, percebe-se que a Igreja e a Polícia continuam merecendo a confiança do povo. O Congresso Nacional, que em 1995 recebeu na ordem de muita confiança o terceiro lugar, foi na pesquisa atual para um dos últimos lugares. Os Sindicatos que tiveram em 1995 um percentual de muita confiança, praticamente igual ao do governo, 
agora receberam cotação muito abaixo da dele. Os Partidos Políticos continuam na posição de merecer pouca confiança.

Pesquisa realizada no ano de 2004 em Santiago com membros da Renovação Carismática Católica, obteve resultados semelhantes. A confiança foi medida através de uma nota entre 0 a 10 e a classificação dessas médias mostra, como pode ser visto na figura seguinte, que a Igreja continua sendo a instituição que inspira maior confiança, seguindo-se a Polícia e depois o Governo. Os Sindicatos e os Meios de Comunicação estão entre as médias mais baixas e os Políticos/Parlamento (Congresso) estão em último lugar como se vê adiante.

Figura 23. Confiança nas instituições - RCC 2004

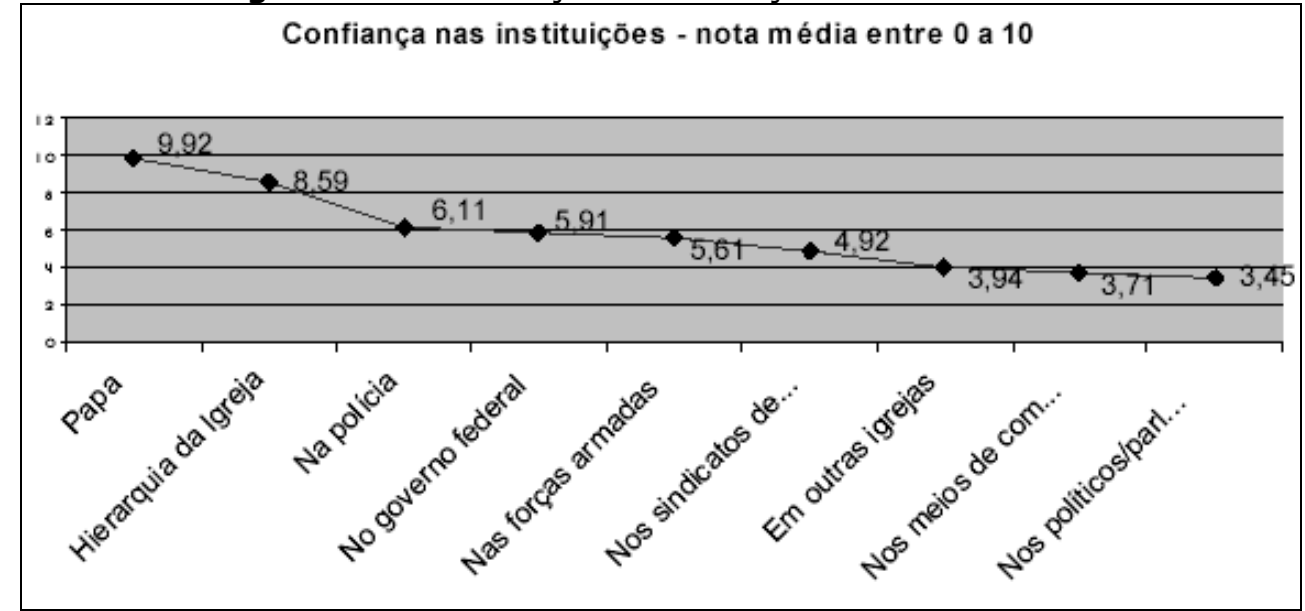

Patrício Valdivieso é Professor Ordinário Adjunto da Pontifícia Universidade Católica de Chile, Pesquisador responsável do projeto FONDECYT 1071073 e Pesquisador Associado do Grupo de Pesquisa sobre Desenvolvimento Sustentável e Capital Social na promoção da Cidadania e Qualidade de vida na América Latina. 